\title{
Sample handling for electronic nose technology: State of the art and future trends
}

DOI:

10.1016/j.trac.2016.06.007

\section{Document Version}

Accepted author manuscript

Link to publication record in Manchester Research Explorer

\section{Citation for published version (APA):}

Burlachenko, J., Kruglenko, I., Snopok, B., \& Persaud, K. (2016). Sample handling for electronic nose technology: State of the art and future trends. TrAC Trends in Analytical Chemistry, 82, 222-236.

https://doi.org/10.1016/j.trac.2016.06.007

\section{Published in:}

TrAC Trends in Analytical Chemistry

\section{Citing this paper}

Please note that where the full-text provided on Manchester Research Explorer is the Author Accepted Manuscript or Proof version this may differ from the final Published version. If citing, it is advised that you check and use the publisher's definitive version.

\section{General rights}

Copyright and moral rights for the publications made accessible in the Research Explorer are retained by the authors and/or other copyright owners and it is a condition of accessing publications that users recognise and abide by the legal requirements associated with these rights.

\section{Takedown policy}

If you believe that this document breaches copyright please refer to the University of Manchester's Takedown Procedures [http://man.ac.uk/04Y6Bo] or contact uml.scholarlycommunications@manchester.ac.uk providing relevant details, so we can investigate your claim.

\section{OPEN ACCESS}




\title{
Sample handling for electronic nose technology: state of the art and future trends
}

\author{
J. Burlachenko ${ }^{\mathrm{a}}$, I. Kruglenko ${ }^{\mathrm{a}}$, B. Snopok ${ }^{\mathrm{a}}$, K. Persaud ${ }^{\mathrm{b}}$ \\ a- National Academy of Sciences of Ukraine, V. E. Lashkaryov Institute of Semiconductor \\ Physics, 03028 Kyiv, prosp. Nauky, 41, Ukraine \\ b- School of Chemical Engineering and Analytical Science, The University of Manchester, PO \\ Box 88, Sackville St, Manchester M60 1QD, UK
}

Recent advances in the sample handling techniques as part of analytical workflow of analysis with electronic nose systems are reviewed. Classic approaches of headspace analysis as well as advanced methods of sample enrichment and dynamic separation are considered and summarized. The efficiency of application of different sampling methods for specific analytical tasks is demonstrated. Special attention is paid to the analysis of present trends of searching the approaches aimed to replace time-consuming and expensive sample preparation procedures with alternative techniques, including development of sensors arrays with adaptive selectivity profiles, creation of sensor interfacial architectures with tunable adsorption properties, advanced experimental data coding and use of classic spectroscopic methods for "virtual" sensor array formation.

Keywords: electronic nose, sampling, sample handling, headspace, sample enrichment, sensor array, sensor, chemical image.

\footnotetext{
Abbreviations list

CI - Chemical Image

DHS - Dynamic Headspace

EN - Electronic Nose

GC - Gas Chromatograph(y)

HS - Headspace

MCM - Multicomponent Chemical Mixture

P\&T - Purge and Trap

QCM - Quartz Crystal Microbalance

SHS - Static Headspace

SPME - Solid Phase Microextraction
} 


\section{INTRODUCTION}

Artificial olfactory systems are of growing importance for development of modern industry and raising the quality of everyday life. Their application increases manufacturing efficiency and environmental safety and makes it possible to control quality of many products used in medicine and housekeeping [1-9]. The concept of electronic nose (EN) is one of the most efficient approaches to solving the problems requiring rapid screening of various complex mixtures [8].

Despite many years in the history of development of artificial olfactory systems, this area still remains at the stage of intense research, both fundamental and applied. They involve, in particular, search for new materials, optimization of measurement procedures and data analysis, as well as optimal sample handling techniques. The long-term experience in that area requires systematization and generalization. Such activity is focused on development of physical transducers and sensitive materials for sensors $[10,11]$ as well as measurement procedures and analysis of multidimensional data [12-14]. However, the level of generalization and formalization in the area of sample preparation, sample introduction and measurement still remains insufficient. So in this review we present a complex consideration of the features of existing sample handling procedures that are characteristic of the EN-type systems of gaseous media recognition. Based on this consideration and analysis, we propose the ways for improvement of analytical systems that use sensor arrays and simulate the biological olfaction to a greater or lesser extent.

The fundamentals of the concept based on arrays of low-selective cross-reactive sensors were laid by Deutsch [15] and realized, for the first time, by Persaud and Dodd [16]. The concept of EN has been formulated by Gardner and Bartlett as "an instrument, which comprises of an array of electronic chemical sensors with partial specificity and an appropriate pattern recognition system, capable of recognizing simple or complex odors" [17]. The basis of EN system is an array of cross-reactive low-selective sensors whose sensitive coatings interact directly with the sample molecules [18]. The sensor elements can be realized on different principles: conductivity sensors, optical sensors, piezoelectric sensors, those based on catalytic FETs, etc. [10] as well as pattern recognition may be realized in different ways [12].

Summarizing recent experiences in the EN field, it is reasonable to extend Gardner and Bartlett's definition. First of all, sensor arrays as a rule are able to interact not only with odors (e.g. volatiles, registered by our sense of smell) but odorless volatiles as well. Moreover, in many cases odorless components (i.e. water, $\mathrm{NO}_{\mathrm{x}}, \mathrm{CO}_{\mathrm{x}}$ etc.) of a studied mixture carry not less useful for analyte identification information than odor ones. Second, terms "Electronic nose" or "Electronic nose technology" are now used not only for "hardware" sensor arrays but for other instruments like, for example, mass spectrometers ("virtual" sensor arrays). Finally, it is also 
necessary to keep in mind that measurement principles of EN are far and away from biological ones and in general case EN does not give the same information about studied objects that a biological nose.

Whatever the type of sensor elements of EN systems, monitoring of multi-component chemical mixtures (MCM) involves the following principal stages:

1. sample preparation that may involve operations of separation and/or concentration of MCM components;

2. measurement of sensors signal and formation environment specific informative "fingerprint" thereon ("chemical image");

3. obtaining of chemical information on MCM by processing the results of measurements and presenting them in terms of calibrated dependencies.

The final result (classification and identification of the studied objects) depends largely on how optimally each of the above stages are realized.

In most cases EN involves the following functional elements: (i) a sample preparation and injection module that ensures contact between the sensors and sample; (ii) a recovery system that is responsible for cleaning of sensor and measuring cell (from here on cell) surfaces, as well as for the system to return to the initial state after each measurement; (iii) a data recording unit that records sensor signals and transforms them to a form acceptable for further processing; (iv) a data processing system that executes classification, identification and other operations, depending on the assigned task.

One of the major contributions to measurement errors is formed at the stage of sample preparation and injection $[19,20]$, since the errors introduced by the present-day instruments are smaller by at least an order of magnitude. Indeed, the premise of obtaining adequate data for analysis is based on the exactness of reproduction of experimental conditions, such as carrier gas velocity, temperature, headspace (HS) volume, vapor concentration and pressure, humidity, etc. $[24,25]$, as well as choosing the optimal way for sample handling in the specific case. Of considerable importance is correct selection of the construction and materials for the experimental sensor or sample chamber and gas tubes for sample delivery [9, 24]. All environmental factors that influence on sensors responses have to be carefully compensated. Otherwise, measurement uncertainty will lead to great informational loss and, in the worst case, to incorrect classification [20].

A biological olfactory system carries out real-time analysis of the external environment without preliminary preparation of objects to be studied. The artificial olfactory systems also tend to maximal operating speed and simplicity; however, as a rule, one cannot avoid the 
procedure of sample preparation for analysis. The following major factors require special additional procedures (in particular, at the sample preparation stage):

1) large number of components in the mixtures to be studied;

2) low concentration of targeted substances that are specific to the character of the given product or process;

3) presence of dominant components (e.g., water) in the mixtures to be studied;

4) sensor cross-sensitivities (similar responses to different substances);

5) aggregation state of the sample (it must be transformed to vapour phase for measurement).

To provide EN versatility, operating speed and portability, the sample preparation must be as simple as possible (and not require much time and complex additional equipment). It has to form such vapour phase environment in contact with the sensor array that is representative of the object under investigation especially concerning the targeted components (or changes it purposefully) as well as make it possible to improve the classification quality and so as to achieve robust recognition. Depending on the type of the assigned objectives, the tasks for sample preparation for analysis are usually as follows: (i) formation of HS (a gaseous or vapour environment that represents component composition of the object under investigation); (ii) sample enrichment, preconcentration, etc. (at low concentration of the targeted components); (iii) filtering and separation (to release target components, separate dominant components, provide separation in time of different components, etc.). A generalized workflow of measurement process with EN is presented in Fig. 1.

\section{FIG1}

This workflow involves HS formation, sample preparation types and introduction of the test sample to the measuring cell (the definition of the test sample see in Section II). The sample preparation procedure can be made either separately (some time before the measurement procedure - e.g., HS preparation) or together with sample injection (use of filters, membranes, gas separation columns, "purge and trap" technology (P\&T), etc.).

Up to now, various approaches to the procedure of sample preparation and injection have not been sufficiently systematized and generalized; there is no established and conventional base terminology in this area. Therefore, the objective of the present review is generalization of approaches to sample handling and systematization and unification of the corresponding basic terminology, as well as an analysis of the ways for further development of systems of sample handling for EN. 


\section{TERMINOLOGY AND DEFINITIONS}

The construction principles for cross-reactive multi-sensor arrays and problems that are solved with them essentially differ from the traditional tasks of gas analysis aimed at determination of certain substances or sample component composition. The system based on the EN technology use the so-called chemical image (CI) of the object to be studied. Classification and identification of CIs are made by comparing them with their corresponding reference patterns from database. Generally CI does not contain information on either the sample composition or presence of certain substances in it [21-23]. So, in the case of measurement with $\mathrm{EN}$, the conventional terminology does not always correspond to the essence of the procedures from the workflow.

To illustrate, the term "sample" becomes ambiguous in the above situation. In the case of EN systems, whatever the aggregate state of the studied object, the sample is a gaseous mixture. It may undergo several stages of preparation before incoming to the cell (where it directly contacts with sensors) and, generally, its component composition does not match with that of the initial sample. So, using different terms for sample before and after treatment looks more relevant.

Below are definitions of terms that we use when considering analytical workflow specific for EN technology:

1) Object: Refers to the representative part of the entity to be considered.

2) Headspace (HS): Refers to the gaseous/vapour medium formed because of evaporation from surface of the object (placed in a hermetic container) that is in equilibrium with it.

3) Sample: Refers to a portion of gaseous/vapour phase selected from the object to be analyzed.

4) Test sample: Refers to a portion of sample used for the performance of test. The test sample may differ from the sample in component composition.

5) Sampling: Refers to any action where the sample or test sample is obtained from the object.

6) Static headspace sampling: Refers to a sampling procedures using closed space for the formation of sample from the object.

7) Static headspace with dynamic injection: Refers to a sampling procedure with a constant flow of headspace through a measurement chamber.

8) Dynamic headspace sampling: Refers to a sampling procedure where the inert buffer gas flows through the object or container with the object or sample. 
9) Pressure balanced sample injection: Refers to sample injection procedures when a sample is placed in a hermetic container of variable volume. The latter shrinks under atmospheric pressure while a portion of sample is moving from the container to the depressurized measurement chamber. This ensures the constant concentration of sample during a measurement.

10) Sample enrichment methods: Refers to procedures directed to increase the content of object specific molecular markers in the sample.

11) Sample handling: Refers to any action applied to the sample before and after the performance of the measurement.

12) Analyte: Refers to the entity to be identified; analyte may be single substance, complex mixture, object, etc.

13) Sample injection: Refers to any action applied to the sample for its interaction with sensors.

14) Injection with temporal separation: Refers to any action applied to the test sample when its components reach the sensors at different times.

15) Chemical image - a way of representation (usually in a graphic form) of sensor array response, containing partial information about the analyte; a "fingerprint" of an analyte in the response space. . CI depends not only on the analyte but on the measurement set-up, injection mode, sampling procedures etc.

16) Analytical workflow: Refers to a sequence of interrelated analytical procedures that is intended for obtaining of qualitative or quantitative characteristics of the studied object. In the case of EN, it involves all stages of analytical analysis (from the choice of the object to be studied to interpretation of the results obtained).

\section{HEADSPACE ANALYSIS, SAMPLE INJECTION AND SYSTEM RECOVERY}

The goal of EN analysis is classification and/or identification of objects. The typical strategy to achieve this goal is presented on Fig. 2. It involves the following steps: HS formation; HS analysis in static or dynamic mode (HS can be modified by enrichment and filtration procedures that will be discussed in the Section IV); sample injection, measurement and formation of chemical images for the classification.

\section{FIG 2}


In this section we consider the most common measurement workflow based on the HS analysis.

\subsection{Headspace formation.}

HS analysis is the most popular sample preparation technique for EN. It does not require special equipment or considerable time for additional procedures. In the most general case, to form HS, an object is held in a hermetic container of constant or variable volume until a preset level of balance (at a constant temperature and pressure) is reached between the sample (solid or liquid) and gas/vapour phase. In this case the vapour phase contains all components of the object in concentrations defined by Henry's constants:

$$
P_{i}=H_{p} \cdot X_{i, l}
$$

where $P_{i}$ is the partial pressure of component $i$ in the vapour phase in units of atm, $X_{i, l}$ is a mole fraction of the component $i$ in the liquid and $H_{p}$ is the Henry's law constant of component $i$ at a given temperature in units of atm. The total vapour pressure is the sum of partial pressures $P_{i}$.

To promote establishment of that equilibrium, some additional sample preparation procedures are usually applied. They are aimed at increasing the free surface contacting with the gaseous phase: grinding, homogenization, etc. - for solid samples and bubbling - for liquids.

Some special procedures may be used in addition to spontaneous establishment of equilibrium between the object and the gaseous phase. Heating and reduced pressure are among the most popular and efficient procedures that promote transition of volatile sample components to gaseous phase (vaporization) [26]. They are successfully used for treatment of such samples as soy beans [27], wheat grains [28, 29], tea [30], packaging materials [31] etc.

The process of gaseous phase formation in which laser irradiation is used for local heating of object surface should be mentioned as well [32]. Depending on the wavelength and intensity of laser irradiation, one or more components evaporates from the object surface. In this way, it is possible to increase concentration of just representative components in the gaseous phase and reduce contribution from uninformative typical components of the studied object. In addition, this technique enables investigation of separate parts of an object (e.g., injured area of patient's skin).

\subsection{Headspace analysis procedures.}

Historically, the headspace analysis has been applied primarily using static methods (static headspace, $S H S$ ): a sensor array and object of investigation are placed in the same container, or 
the sample is injected into a hermetic measuring cell with sensors after HS formation has been achieved [16, 26, 33]. Using Henry's law volatility constants it's possible to estimate the composition of the gaseous phase if the composition of the measurement sample is known. This opens the way for optimal planning of both sampling handling and measurement procedures [34, 35]. The SHS advantages are simplicity, low price and absence of specific additional equipment (pumps, mixers, etc.). At the same time, need for long-term exposures and allowance for components adsorption on the cell walls and construction elements, complications with interpretation of adsorption kinetics (sample concentration varies in the course of analysis), etc. cause inefficiency of SHS analysis of MCM containing low-concentration components. In such cases, it is reasonable to apply other sample preparation techniques (for more detail, see Section IV).

Dynamic headspace $(D H S)$ may be realized in several ways differing only in the area of free object surface from which vaporization of volatile object components may occur. The classical ways of DHS formation involve the following:

1. A sample is formed during the course of inert gas flowing (with constant velocity and temperature) over the studied object surface. The concentration of volatile components is determined by the interrelation between the carrier gas flow-rate and efficiency of molecular evaporation from the free object surface (that depends on the evaporator geometry, temperature, object properties, etc.) [26, 36-38].

2. Bubbling in a case of liquid or finely-dispersed objects. An inert carrier gas passes through the object volume [26]. In this case, a constant high concentration of volatile components is set in the system because the surface from which evaporation occurs is very large (it is determined by the area of surface of carrier gas bubbles). This concentration is limited only by the concentration of saturated vapor at a given temperature [39].

The sample composition may vary with time if the object volume is small and the object of investigation is MCM with different compositions of components whose volatilities differ considerably. That is why it is necessary to use a new volume of the same mixture when making repeated experiments. In a case of solid objects of investigations, the level of dispersion (the total free surface of a solid) also affects the sample formation [40].

Among the DHS advantages are constant and high concentration and component composition of gaseous sample (since in such a case adsorption of analyte molecules on the cell walls and gas tubes surfaces is compensated by inflow of molecules from the flux) and capability of sample continuous generation.

More information about methods of HS analysis can be found in [41]. 
The application area of HS analysis is very wide: from analysis of drinks and foodstuffs to medicine and environmental monitoring [1-2, 4, 42-44].

\subsection{Sample injection procedures.}

The test samples (HS, extract, etc.) may be injected into the measuring cell using static or dynamic methods (in a case of HS these are SHS and DHS - see subsection 3.2). In the static way, the sensor array is located directly in the object HS or the sample is injected to the cell without a flow either manually or using a piston autosampler. The parameters that are to be checked and can be optimized are temperature, pressure, sample concentration, cell volume and construction $[12,26,43]$. The main advantage of the static way of sample injection is its simplicity and minimal requirements for additional equipment.

The dynamic method of sample injection uses a flow cell through which a test sample flows with a constant velocity. In the literature the dynamic way is often associated with the purge-and-trap method. However, this is not quite right: along with the P\&T, DHS, SH with dynamic injection (in particular, pressure balanced HS), bubbling and every other methods related to flowing of a gaseous test sample through a cell are assigned to the dynamic methods. (For P\&T and other sample enrichment methods see Section IV.) Three most common ways of the realization of DHS injection are shown on Fig. 3. The dynamic techniques require additional equipment. However, they ensure more correct measurements owing, in particular, to compensation of adsorption of part of MCM molecules on the walls of the cell, tubes, etc. (the adsorbed molecules are replaced by new ones from the flow) and permit application of simple automatic systems for dynamic dilution of sample down to the concentration necessary for analysis.

\section{FIG 3}

The typical method adopted for dynamic sample injection is pumping a sample from a hermetic container through the cell. The main problem in this case is pressure change in the container with a sample, or sample dilution (if part of sample volume is replaced with equivalent volume of an inert gas to maintain constant pressure). A nontrivial solution of the above problem is placing the sample in a container of variable volume (e.g., an elastic plastic bag). As sample is being taken off, the container shrinks under atmospheric pressure. Thus, the sample concentration in the container remains constant. Before sample injection, the measuring cell is placed under reduced pressure, while there is atmospheric pressure in the container. Because of generated pressure difference, the cell is filled with the sample, without pressure change in the 
container with the sample. Such an approach makes it possible to estimate adsorption-desorption kinetics at the sensor surfaces just from the first seconds of measurement, because variation of sample concentration in the measuring cell occurs quickly and does not affect the character of sensor responses. This approach (called pressure balanced sample injection) can be used both for static and dynamic sample injection procedures $[26,45,46]$.

The construction and materials of sample injection system are of great importance for any type of sample injection. In particular, all the paths and junctions through which a sample passes have to be made of inert materials with minimal adsorptivity to various compounds; the materials used in construction and tubes must have no volatile components $[9,26]$. As to the measuring cell construction, it is of importance to a greater extent for dynamic sample injection techniques. For example, to register with maximal accuracy CI changes at the initial parts of the adsorption curves, it is necessary to ensure simultaneous presentation of a gaseous mixture to different sensors in array. In this case, the sensors are placed in separate cells equally spaced from the inlet for test sample injection [47].

\subsection{Effect of parameters of sample injection systems on effectiveness of EN.}

The effect of sample injection technique (static and dynamic) on reproducibility and discrimination of studied objects is considered in the review [14]. Its authors state that better reproducibility is provided with the static technique of sample injection. As to the discrimination ability of the system, it depends on what response features are analyzed and how the measurement in the dynamic mode is optimized. According to this, we consider in this Section predominantly the dynamic mode of sample introduction: it enables to vary analysis conditions in a much greater extent than the static one. Most attention is paid to the conditions of adequate measurement of kinetic dependences of sensor responses as well as choosing of system parameters that could ensure a constant sample concentration in the measuring cell and rapid (ideally, instant) filling of its volume.

The list of factors affecting the quality of classification on all stages of EN measurement workflow is presented on Fig. 4. The main reasons for the classification downgrade are bad reproducibility, information loss and signal distortion. The scheme on Fig. 4 demonstrates how mistakes at different measurement stages (sampling, injection, measurement) influence on the experimental results.

\section{FIG 4}


The main parameters at the injection stage are sample flow-rate, injection pressure drop, temperature and pressure. These are considered in more detail in the following sections.

\subsubsection{Sample flow-rate.}

To ensure constant sample concentration, it is necessary to maintain the carrier gas velocity and temperature constant during the whole experiment. In this case, the gas flow-rate has to optimally correlate with both the evaporation rate of volatile components of the studied object and the rate of molecules transfer from the test sample bulk to the sensor surface due to adsorption. Indeed, at too low flow-rate, a situation may occur that concentrations of some gaseous mixture components change because the number of sample molecules incoming to the sensor surface exceeds that incoming to the cell with carrier gas. In the review [48] such a situation is called "transport-limited adsorption".

In the case of DHS, both sample concentration and composition depend on the amount of carrier gas incoming to the evaporator. To illustrate, the concentration of less volatile substances in HS may decrease at too high flow-rates. On the other hand, at high flow-rates liquid drops or powder particles (depending on the aggregate state of the object) may get to the cell.

The velocity of sample flow, as well as the lines of sample supply to the cell and its geometry, determine such an important parameter as flow laminarity. Of course, for a gaseous phase this parameter is of lesser importance than for a liquid phase [48], since the diffusion coefficients in a gaseous phase are sufficiently high. However, turbulent disturbances in a closed cell volume may lead to spatial non-uniformity of test sample concentration, pressure, velocity etc. near different sensors of the array, at least in the very beginning of measurement. That is why it is necessary to pay considerable attention to geometry of the cell as well as arrangement of sensor elements in it.

\subsubsection{Injection pressure drop.}

The initial parts of kinetic curves of sensor's responses are subjected to considerable distortions because of spatial non-uniformity at sample injection in the cell. One of substantial problems at this stage is a pressure jump in the course of injection. The cell has to be filled up with the sample sufficiently rapidly to ensure analysis of adsorption kinetics at the beginning of measurement. However, this requirement contradicts the necessity to provide equal conditions (pressure, velocity, concentration) all the time of measurement as well as at every point of the cell (at least, there where the sensors are located). Indeed, it is difficult (or even impossible) to ensure flow laminarity at too abrupt pressure jump in the moment of sample supply. This fact, along with the other ones (e.g., sensor vibration at an abrupt pressure jump), leads to the 
appearance of certain transient processes during the first seconds of measurement, thus distorting analyte-specific adsorption processes at the sensors' surfaces.

The sample injection mode when constant flow of inert gas through the cell is replaced by the same flow of inert gas carrying the test sample can solve this problem. In this case the pressure in the cell does not change during the sample injection. However, in this case the concentration of test sample in the cell increases too slowly, and so limits the possibility of analysis of the adsorption kinetics. An alternative solution is currently being developed in V. Lashkaryov Institute of Semiconductor Physics, Kyiv. The solution is to use a small mesh net in the cell inlet that serves as a peculiar flow turbulence promoter and reduces hydroimpact. The net material and configuration must ensure constancy of sample composition.

\subsubsection{Temperature and pressure.}

Temperature and pressure are the strongest factors affecting adsorption-desorption equilibrium [26]. Realization of pressure control is technically complicated; in contrast, temperature control can be realized rather easily. One has to consider separately the object temperature, temperature of gaseous phase in the measuring cell and sensors' temperature. The object temperature affects the process of object components evaporation; since Henry's constants of different components of an object have different temperature dependences, their ratio in the gas phase will be different at different temperatures. In this way the EN system may consider the same mixture at different temperatures as different mixtures.

The HS and sensors' temperatures affect the adsorption-desorption equilibrium; in addition, the sensors' temperature affects the sensor coating functionality.

The effect of cell and HS temperatures on reproducibility of measurement results and analyte discrimination is studied in [14]. The cell temperature affects reproducibility: it improves as cell temperature increases from $35^{\circ} \mathrm{C}$ up to $60^{\circ} \mathrm{C}$. The author of [14] explains this effect by a more uniform analyte distribution over cell at higher temperature. The HS temperature affects also essentially on reproducibility; however, in this case reproducibility improves at lower temperatures of HS generation. Both above factors practically do not affect analytes discrimination. The maintenance of a constant temperature when performing measurements is important as well [45]. To illustrate, it was shown in [49] that satisfactory classification in the case of sensors based on conducting polymers with use of neural network can only be obtained if the operating temperatures is maintained constant with accuracy within 3-4 \%.

\subsubsection{Humidity.}

Humidity is another one important factor that affects sampling and measurement [50]. Indeed, water is usually present everywhere at least at trace quantity. Since many sensor coatings are sensitive to water, it can mask the contribution of other components of water-based mixtures. 
This leads to the formation of similar chemical images that cannot be effectively classified. So, the possible influence of humidity has to be taken into account during both sampling and measurement procedures.

Using special conditions with essential reduction of water content can help on the sample preparation stage for solid objects: it excludes water sorption during grinding or homogenization of the sample. For liquid samples a hydrophobic liquid may be used for sample dissolution [51]. Another way of the reduction of water vapour influence is using the sensitive layers not sensitive to water.

The possible distortion of sensor response may not be only due to the adsorption processes but also because of secondary processes induced by water, for example swelling [38, 52]. At the same time the effects of analyte induced water adsorbtion may be used for design and development of unique ultrasensitive approaches with detection limit up to $10^{-17} \mathrm{~g} / \mathrm{L}$ of potent xenobiotics (see 7.2, [53]).

\subsection{The techniques for sensor surface recovery and reproduction.}

Reproducibility of measurement results to a large degree depends on the capability to restore the surfaces of sensors' sensitive elements to the initial stable state. When performing various analyses, the sensors' sensitive surfaces must retain all their properties and revert to the initial state after each measurement.

\subsubsection{Recovery with inert gas flow and reduced pressure.}

This technique for recovery of sensors' surfaces is the most widespread. It does not require additional equipment in the dynamic mode of sample injection if the cleaning is performed using the same flow paths as for the sample transport to the cell. Unfortunately, in many cases return of sensor's responses to the initial state requires much time. To reduce the time needed to return to baseline, various solutions for switching stronger flows of carrier gas directly onto the sensitive elements are used (directed nozzles, etc.). This makes it possible to essentially reduce characteristic time of sensors' responses restoration. One more version of cleaning is reduced pressure: the sample is evacuated from the cell and vacuum is maintained in it for a certain time.

In the case of static sample injection, an additional pump or compressor has to be specially installed for cell cleaning after measurement.

\subsubsection{Temperature recovery.}

Blowing or reduced pressure are not always sufficient for complete cleaning of sensors' surfaces. If adsorbed molecules bonding with the surface is rather strong, then thermal desorption is applied for surface recovery. This technique (consisting of sensor heating up to a temperature at which all undesirable molecules are desorbed from the surface) is predominantly 
applied to inorganic sensitive elements that are resistant to high temperatures. In the case of organic layers, it can be used for heat-resistant substances only. Otherwise the effect of temperature may lead to surface restructuring with changing adsorption properties of the surface.

\subsubsection{Application of solvents.}

In some cases, it is impossible to get complete restoration of the initial state of sensors' sensitive layers, even after application of traditional cleaning procedures. Sometimes (especially in the case of organic sensitive coatings) not only contamination of surface occurs but also it is modified (restructuring, formation of surface complexes, chemisorption etc.) If the sample has less volatile organic components and solvents (e.g., ethylene) capable of initiating polymorphic modifications of the sensor element surface, then it is reasonable to perform intermediate recovery with single-component solvents that can return the surface to the reference state. For example, efficiency of such an approach was shown in [54] for analysis of brandies that demonstrated irreproducible kinetic behavior of sensors. Application of high concentrations of ethanol vapor as a recovery agent made it possible to return sensors' surfaces to the initial state.

\section{SAMPLE ENRICHMENT METHODS}

When analyzing MCM with low concentration of the targeted mixture components, CI obtained from the data of the array of low-selectivity sensors may be insufficiently unique for its successful identification. The situation becomes more complicated at the presence of predominant components, such as alcohol and water (in the case of drinks or medical drugs) that "mask" sensor's responses to more informative (specific for the object under investigation) components.

For example, the prospects for EN application to control the process of beer production are considered in the review [55]. Its authors prove that the approaches using traditional sample handling procedures do not give adequate results in that case. Similar conclusions have been made by the authors of [56] and [57] dealing with identification of teas and analysis of human expired air: application of a gas trap and preconcentration using adsorbents to remove water vapor made it possible to improve analysis efficiency in the both cases.

Thus, in some cases that HS analysis cannot permit to obtain unique information on the studied object, additional procedures (such as P\&T and solid phase microextraction (SPME)) are applied at the sample preparation stage and more specific sensors or special procedures for data processing are used [55]. In spite of the wide diversity of sample enrichment methods proposed in literature, all of them eventually are directed to increase of concentration for specific 
substances those in the best way characterize the object under consideration. The main methods of preconcentration are considered in more detail in the following sections.

\subsection{Solid phase microextraction.}

Usually SPME uses silica fiber coated with a layer of adsorbent that is selective to the targeted components or incapable of binding the predominant components, such as water or alcohol [58-62]. The fiber is placed in the object headspace or immersed in it (if the object is liquid). The volatile components concentrate at its surface and in the bulk because of adsorption and diffusion. After this the fiber is heated, the molecules of volatile components desorb and are introduced to the cell with sensors [43].

HS/SPME (exposure in the headspace rather than immersion in liquid object) is used more often. It ensures higher selectivity and practical efficiency: a fiber not in contact with liquid becomes contaminated or dissolved to a lesser degree. With this sampling mode a contribution of nonspecific or predominant matrix components decreases as well as the extraction time [63].

Organic (usually polymer) and inorganic (porous solid) sorbents as well as their combinations may serve as coatings. The most widespread commercially available coatings are Polydimethylosiloxane (PDMS), Polydimethylsiloxane/divinylbenze (PDMS/DVB), Polyacrylate (PA), Carboxen/polydimethylsiloxane (CAR/PDMS), Carbowax/divinylbenzene (CW/DVB), etc. [63, 64]. Many other approaches have been proposed to form selective sorbents for solving specific analytical tasks using sol-gel procedures, in-tube extraction, electrochemical coating deposition, etc. [64, 65].

The SPME procedure may be optimized for any specific case. Choosing of adsorbent material and its thickness, temperature of HS and studied object, desorption temperature, fiber exposure time in HS, etc. depend on the studied object nature and the assigned task. To illustrate, in the case of mixtures' analysis, the time of exposure of a fiber with adsorbent in HS is of importance. The time of establishment of adsorption-desorption equilibrium is different for different mixture components, and fiber adsorption capacity is limited. So the effect of replacement of previously adsorbed molecules of low molecular mass with other components of higher molecular mass may occur. To solve this problem, it is necessary to reduce the exposure time of the fiber in the HS [63].

The most widespread SPME applications are analysis of food [65-69] (in particular, fruits [71], olive oils [72] and wines [73]) and samples of biological origin [74], as well as environmental monitoring [75, 76], and search for explosives [77]. The advantages of SPME are ease of integration into devices, low sample consumption, possibility of increasing system sensitivity and selectivity at adequate choice of adsorbent, and relatively low cost of analysis 
[63]. Among the SPME drawbacks are, first of all, fiber aging and relatively low reproducibility of analysis results obtained at different laboratories and when using different fibers (even made by the same manufacturer). The other problems are relatively small number of commercially available sorbents, their aging and complexity of method automation [63].

\subsection{Purge and trap.}

In this method, an inert gas passes through the object (gaseous, liquid or solid). The volatile components are captured by a special adsorbent (trap). The trap is heated, the adsorbate is desorbed, and the trapped molecules are supplied for measurement [43]. The most widespread adsorbents are Tenax (general purpose trapping agent), Chromosorb 106, graphitized carbons (Carbotrap B, C), carbon molecular sieves, silica gel (for polar compounds), Tenax/silica gel/charcoal trap, etc. [68, 78].

The parameters that can be optimized in this case are purge time, adsorbent heating temperature and temperature of sensors and cell. An important parameter is trap temperature during of sampling as well as at desorption. Optimal trap temperature at sampling allow the wider range of volatile substances to be trapped from the sample. The trap temperature during desorption may be used to expand/narrow the range of volatile substances that are desorbed. At lower temperatures, only the most volatile molecules of low molecular mass will be desorbed; the contribution of molecules with higher molecular mass increases as temperature grows.

One of the most important characteristic of a trap is its loading capacity. If the latter is saturated, then volatiles will break through. The volume of gas that causes the trap to be overloaded is called the breakthrough volume. This breakthrough can however be partially avoided by carefully choosing the most adequate trapping material and working conditions [69].

P\&T has found especially wide utility for analysis of drinks and food stuffs. Most adsorbents do not take up alcohol and water. That is why P\&T is successfully employed for handling of such objects as alcohol drinks, coffee, juices, meat products, etc. [64, 78]. To illustrate, by applying different methods of wine aroma extraction (SHS with dynamic injection, SPME and P\&T) and comparing efficiencies of classification, it was determined $[64,79,80]$ that the highest sensor responses were observed in the case of HS (caused by alcohol contribution); however, the best discrimination was achieved in the cases of SPME and P\&T [79]. Better results were also obtained using P\&T for threshold detection and concentration quantification of aromatic compounds in wines [80]. 


\subsection{Other extraction methods.}

The sample enrichment methods SPME and P\&T are among those most often cited in the literature on sample handling for analysis with EN. However, the list of such methods is much wider. One should recall Solid Phase Dynamic Extraction (SPDE), Stir Bar Sorptive Extraction (SBSE), In Tube Extraction (ITEX), Inside-Needle Dynamic Extraction (INDEX), etc. [33, 43]. The operation principle of these methods is similar to that of the abovementioned. The distinction lies in adsorbent material, its quantity and arrangement (inside a tube or needle, at the magnetic bar surface, etc.), way of making contact with a sample (blowing a tube/needle, immersion into analyte, placement in HS, etc.) and ways of release of adsorbed molecules for further analysis (heating, blowing carrier gas etc).

When choosing a particular approach, one should be guided by several factors: features of the assigned task, necessity to combine EN system with other systems, cost of materials (adsorbents, fibers, etc.), and so on. For use of the methods (considered in this Section) in commercially available systems see Table 1 (subsections 6.2).

\section{V.METHODS OF GAS SAMPLE FORMATION WITH DYNAMIC SEPARATION}

Among the most interesting methods of sample handling are the dynamic separation ones. They make it possible to extract the most informative sample components making concurrently direct analysis of them.

The idea lies in extraction of certain components from a mixture (that properly acts as sample enrichment) or temporal and/or spatial separation by analogy with functioning of biological nose $[9,81-83]$. In the latter case, EN analyzes not the mixture as a whole but its individual components (or their groups). They arrive at the sensor array in a certain sequence that is determined by the features of the used gas separation column. Among the most general methods of gas sample separation are low pressure filtration, "distributed" chromatographic phases and chromatographic partitioning in the high pressure columns.

Temporal and/or spatial separation of different mixture components makes it possible to obtain more adequate and representative information on the studied objects, especially if the initial ratios between the different components are not known [82, 83]. It is well known that less volatile (high boiling) substances have higher energy of adsorption than high volatile (low boiling) ones [84]. Therefore less volatile components of an analyzed mixture produce more marked contribution into summary CI of the mixture than highly volatile (low boiling) ones, being in equal concentration. That is why separation of less volatile components serves as 
sample enrichment and enables to get information on highly volatile components that usually are characteristic markers of objects under investigation. Three different separation techniques are shown on Fig.5. They include separation with viscous matrix, low-pressure and high-pressure columns.

\section{FIG 5}

\subsection{Filtering and low-pressure gas separation columns.}

The methods applying filtration and low pressure gas separation columns use ideology of spatial or chemical restriction of motion for some components of a complex mixture (fig. 5, a). The simplest versions are gas-distributing membranes (with pores of a specified size) that prevent penetration of molecular components whose size exceeds some limiting value. Similar systems built of hydrophilic materials permit the passage through them of those components only that are capable of mixing (dissolving) with the membrane material (thus intercepting hydrophilic water or alcohol). The low pressure columns are made similarly but are of much larger thickness and frequently are built of porous inorganic materials whose internal porous system is modified in a preset way according to the objectives of analysis. Generally this type of sample handling involves all the methods and techniques that change composition of the sample gaseous phase by means of irreversible removal of part of its components (thus keeping them from entering the test sample) before analysis with a sensor array.

Such systems are mostly used for analysis of the samples having predominant components that mask other (more informative) components. Studied objects' HS are passed through various filters, membranes, catalytic filaments, etc. [85-87].

A classical method of membranes' application is pervaporation. Most often used is the vacuum pervaporation: a liquid object at normal pressure passes through a membrane after which there is a cell with vacuum. Depending on the membrane selective loading properties, one or other of volatile components comes to the cell and forms a gaseous phase for further analysis [88]. The membrane separators are often placed on the way of the sample to the cell [87].

Inorganic molecular sieves are one of the most acceptable materials for low pressure columns because of their extremely low price and possibilities for modification of their internal porous system. Since the pore size of these structures determines the size of molecules that can be adsorbed at the inner surface, they can be used as sieves as well as sorbents. To illustrate, type-A zeolite is a typical dryer (highly selective to water), while type-X zeolite is a molecular sieve that can also adsorb at inner surfaces organic molecules of larger size (usually those of polar or slightly polar compounds). This makes it possible to make selective adsorption of 
molecules of polar, unsaturated and aromatic compounds of appropriate sizes, even without additional modification of internal pore surfaces of sorbents.

Use of gas separation columns filled with zeolites is considered in [89]. A column is placed immediately before the input to a sensor array on the way to HS formed by bubbling. At the given temperature and pressure, part of mixture components remains in the column material owing to sorption, while the targeted components come to analysis. Thus, different mixture components are separated, and a more informative response is formed at the sensor array output. After the column loading capacity for the sorbed components is reached, the column is freed of the sorbed components by increasing temperature or reducing pressure. Zeolites are rather stable, both chemically and thermally. They quickly and completely restore their activity at temperatures in the $300-700^{\circ} \mathrm{C}$ range and can be used many times. To illustrate, the approach to separation of MCM components in real-time mode using a low pressure gas separation column in a case that some mixture component is predominant is realized in [90].

5.2. Application of high-pressure gas separation columns: a combined chromatograph-EN system.

The systems with high pressure columns in which EN serves as a detector in the standard gas chromatography (GC) configuration principally differ from those considered in the subsection 5.1. In essence, in GC-EN systems a sample does not change in composition but is separated in its components each of which is supplied for analysis in different instance of time (fig. 5, b). As a result, the combination of GC with concept of EN opens the way for advanced chemical imaging of complex chemical mediums with direct identification of their components $[23,90-94]$.

GC uses a capability of column material to retain individual components of a complex mixture for different times. As a result, a sequence of substances with different retention times is formed at the EN input. Application of EN systems for analysis of the composition of similar MCMs was essentially stimulated in recent years owing to understanding of the basic mechanisms of olfaction and some achievements in instrumentation design [93-96]. All the advantages and disadvantages of GC-EN approach are determined by the possibilities of separation column, as well as in any other method of chromatographic analysis. For a brief description of the history of development of the above approach, an analysis of the recent advances in the area and original results on determination of composition of complex mixtures using the GC-EN concept see [97 - 100]. 


\subsection{Biologically inspired separation techniques: separation processes utilizing the}

effect of matrix viscosity on diffusion rate constants of complex mixtures components.

Initial separation and concentration of odorants in an olfactory system is the result of their different rates under diffusion through the mucus layer depending upon the molecular mass and availability of odorant-binding proteins. Thus, the mucus layer (above $20 \mu \mathrm{m}$ thick) demonstrates properties inherent in the classical chromatographic phases; odorants separation in the space-time continuum is the result of their difference in molecular masses and chemical functionalities [81]. The concept of "continuous \& distributed" chromatographic phase is similar to natural mucus layer; the composition of a sample is modified because of diffusion limited spatial-temporal separation of mixture components as moving to the surface through a highviscosity matrix (fig. $5, \mathrm{c}$ ).

In most cases, the target and matrix components are chemical compounds belonging to different chemical classes and having different physico-chemical characteristics. This affects the gaseous phase composition because a flow from the surface of such a system depends on the diffusion coefficients of different MCM components. To illustrate, glycerin matrices (that readily dissolve alcohols and water) were used in [101] as diffusion-controlled media for diffusion separation of MCM. Such a matrix makes it possible to prolong transition to a gaseous phase of highly volatile MCM components, as well as separate in time lighter and heavier components of the MCM under investigation. Such glycerin matrices may be also used as separate layers: a glycerin layer is placed over the liquid sample surface (without intermixing); diffusion of the lighter components through the glycerin layer proceeds slowly and depends on the glycerin layer thickness. Another example: a mixture of a sample and glycerin matrix makes it possible to form more informative CI of complex mixtures [101]. A similar approach was used in [102] to separate high-molecular compounds, such as proteins.

It is important to stress the actual problems associated with vaporization of compounds with very low vapor pressure like explosives, potent high molecule weight xenobiotics e.g. drugs, toxins or waste products of pathogenic microorganisms etc. The typical sampling procedures of those compounds include (i) a particle collection of the sample (capture of particles of dust on membrane or using wipe sampling materials) [103], dissolution in suitable liquid through bubbling [104] etc.; (ii) concentration, in the case of trace detection, followed by (iii) thermal desorption [105]. It is reasonable to note that validated sampling protocols successfully used for ion mobility spectroscopy may be efficiently used in this case [106]. 


\section{A REVIEW OF PATENTED AND COMMERCIALLY AVAILABLE SOLUTIONS}

\subsection{Patents.}

The sample handling and injection methods for EN systems are rather insufficiently patent protected. The vast majority of patents are relevant to gas analysis with EN systems, while too little attention is given to sample handling. As a rule, conventional HS sampling with static or dynamic sample injection is considered. Following is a short list of patented original solutions concerning sample handling for analysis with EN.

In the patent [47] a system of gas sample is described. It involves a thermal conditioning unit (that ensures sample heating up to a necessary temperature), the main channel of sample injection and independent cells with sensors. The main injection channel has holes through which the flow is divided and comes to each sensor separately. So identity of measurement conditions for each sensor is ensured because of avoidance of thermal interferences between sensors.

The authors of [107] propose a gas collection and analysis system that involves a filter, preconcentrator, gas chromatograph (GC) and sensor array. Different versions of combining, application and realization of experimental setup elements are described. In particular, a filter is used if there are solid particles in the sample; dehydration and preconcentration are made if necessary. The sensor elements register signals from mixture components separated in time with GC. The same authors described similar systems intended for medical applications [108].

A procedure for analysis of soybeans is proposed in [109]. A soybean sample is heated and HS is analyzed.

A method of sample preparation for analysis of food products is described in the patent [110]. A food product sample is placed near an aerosol collector for some time (it may be also aired). The aerosol particles are collected and then are going with a gas flow to EN.

A sensor array for monitoring of fire safety in closed space is presented in [111]. A dynamic sample injection with filtering is used. The filter removes smoke particles to protect sensors' surfaces as well as dries the sample to reduce the effect of water vapor on sensors' response.

\subsection{Commercially available sample handling systems.}

There are rather many manufacturers in the field of chemical sensors (particularly EN systems) in the market $[4,9,81]$. However, the number of special-purpose sample handling systems for EN is rather limited. As a rule, commercially available systems are intended for other uses, such as GC. At the same time, a considerable part of them can be adapted for sample 
handling to perform analysis with EN. Table 1 presents a list and brief description of sample handling used with EN, as well as such that could be successfully applied in that area.

\section{Table 1.}

\section{TRENDS AND PROSPECTS}

The discussed in the review sample handling procedures enable to raise informative content of the sample by changing its composition and increasing contribution from the targeted components (unique identifiers of the studied object). However, most of the considered approaches involve use of massive additional equipment as well as procedures and reagents which increases time and cost of analysis and require presence of experienced personnel. In line with that one of the main directions for future development in the field of EN instrumentation is minimization of sample handling procedures, specific equipment and additional supplements.

In this Section we will consider some approaches for increasing the information content of measurements by the possibility of controlling of the interaction of a sensitive material with different mixture's components. This possibility is based on the material's adsorption capacity dependence on (1) the external conditions (for example illumination, for the photosensitive materials); (2) time period of signal's informative part registration (adsorption/desorption constants differs for different compounds) and (3) the occurrence of secondary processes (e.g. swelling). In general it is possible to say that in this case the change of sample's composition is replaced by the controlling of sensitive layer's properties.

In such a way, we consider some alternative modern approaches and methods to achieve the goals that are usually specific for the sample handling procedures but are realized in a different ways. The following typical examples of such approaches which are indicating the present trends and whose efficiency has been demonstrated experimentally will be considered: 1) variation of selectivity profile of a sensor array by using tunable sensitive coating materials controlled by external influences, 2) use of advanced interfacial architectures of sensitive layers demonstrating analyte specific secondary processes, 3) new methods of analyte-specific information extraction from multidimensional response space of a multisensor array in dynamic mode, and 4) further diffusion of EN concepts on classical techniques for multi-analytical detection resulting in "virtual sensing" assays. 


\subsection{Sensitive layers with externally tunable sensitivity profile}

For reversible gas sensors used in the EN systems, adsorption-desorption equilibrium at sensitive surface essentially depends on external conditions, in particular, illumination, temperature, electric field, etc. This enables varying adsorption capacity of sensor surface in respect to definite components and consequently adapting an array's selectivity profile for a specific task without replacement of sensor elements.

Known approaches of realization of this idea are temperature modulation, thermal cycling or temperature programming $[14,116-120]$, spectral-selective illumination $[14,121]$. To illustrate, in [120] it was shown (by using a chemiresistor microsensor array) that responses of one and the same sensor obtained in different temperature ranges carry different analytical information; this enables to obtain additional information using the same sensors. The examples of illumination usage are increase of reproducibility and sensitivity of semiconductor gas sensors based on inorganic films $\mathrm{SnO}_{2}, \mathrm{In}_{2} \mathrm{O}, \mathrm{ZnO}$ etc. towards some analytes $\left(\mathrm{CO}, \mathrm{NO}_{2}\right.$, formaldehyde, alcohols etc.) [121-123]. Moreover, UV irradiation enables semiconductor sensors to operate at room temperature [122-123].

In the above cases, the external factor affected not only the adsorption processes but the measured quantity (e.g., current by charge carrier photogeneration) as well. The use of masssensitive sensors allows investigation of illumination influence on the adsorption process themselves. This is important for understanding the adsorption-desorption processes occurring on a sensors surface under illumination. It was shown that spectral-selective illumination can be efficiently applied to control sensitivity profile of mass-sensitive sensors/arrays based on quartz crystal microbalance (QCM). Along with increase of discrimination ability of a sensor array and considerable reduction of adsorption capacity of a photosensitive coating (phthalocyanines) towards water and ethyl alcohol, application of illumination made it possible to essentially increase data reproducibility as well as to reduce time of measurement [124]; it was successfully demonstrated by analysis of pharmaceutical preparations [125] and of water and alcohol mixtures of amines [46] under UV and VIS illumination correspondingly. Therefore, use of illumination may become an alternative to the additional stages of sample handling (such as dealcoholization) that require increase of time of measurement as well as bulky and costly equipment. Thus, on the one hand, application of such an approach enables to increase information content from a multisensor array without changing the number of sensors, and on the other hand, it affects the contribution from one or other (predominant) mixture components to formation of CI of the studied substance. 
The future developments in this direction assume wide screening of both potential sensitive layers and suitable external influences and requires deeper understanding the basic mechanisms of selectivity profile changes.

\subsection{Structural reorganization in sensing surface architecture induced by analyte}

The features of the secondary processes of structural reorganization of surface architecture induced by analyte adsorption may be used for obtaining of additional analyte-specific information from low-selective sensor elements of the array. For example, swelling of some organic materials interacting with vapors of different substances is applied to make efficient resistive gas sensors using percolation conductivity of conducting particles (intercalated in a polymer matrix); the spacing between those particles depends on the adsorption-induced volume change in a composite material of the sensitive element [126-129]. In a case of acoustic transducers, the adsorption-induced variations of visco-elastic characteristics of the sensitive layer result in specific features of sensor response, e.g. change of response kinetics or even "reverse" response, or anti-Sauerbrey behavior (e.g. a signal decreases in response on a sample exposure while normally it has to increase) [52, 130-131].

Along with changes in mechanical characteristics of sensitive layer, analyte adsorption may induce variation of adsorption capacity of the surface architecture towards other mixture components. To illustrate, it was shown that the variations in the QCM response are due to the change of water-binding capacity of the biorecognition layer induced by protein transformations initiated by the binding of ethinylestradiol molecules [53].

By generalizing the above specific examples of applying post-adsorption processes of reversible structural reorganization of sensitive architecture for purposes of analysis, one can state that in some cases it is possible to get significant analyte-specific information that increases uniqueness of analyte CI and cannot be obtained in a different way.

The successful realization of the concept requires comprehensive design of sensitive layer for the false-free detection of analytes of different nature. It seems evident that chemists are presently in a strong position to have significant impact on future developments in materials for sensitive layers, especially, concerning adaptive supramolecular interfacial architectures with tunable spatial organization.

\subsection{Multisensor array response parameterization}

The informational content of CI can be sufficiently increased by choosing the optimal set of sensors' responses parameters for its formation. For example, CI formed on the basis of sensors response at some specific moments during the adsorption process can give much better 
results than those built on signals' saturation values. This effect is called "kinetic discrimination effect" and is explained by the significant difference of adsorption constant rates for different MCM components and the occurrence of local processes more or less expressed within the definite periods of time. This opens the way for the direct optimization of the procedure of response space parameterization and finding the best time interval for the formation of CI with maximum information content. Correct application of the kinetic discrimination effect makes it possible to essentially increase the efficiency of cross-selective sensor arrays for gas analysis $[23,40,134-138]$.

\section{4. "Virtual" sensor arrays}

Spectroscopic techniques, chromatography, mass-spectrometry and other classical techniques capable of direct detection of multiple analytes during the same test are usually to be among the direct methods for CI formation using 'virtual arrays'. In this case CI may be formed using various "virtual" sensors represented by specific for each method value of operational parameter (e.g. mass-to-charge ratios in mass-spectrometry, Raman shift in Raman spectroscopy, retention time in chromatography etc.) [3, 8]. In particular, new advancement in SERS, TERS and similar Raman based techniques open the way for direct multi-analyte detection of complex mixtures of different nature [139]. Although these techniques are not completely relevant to EN technology as there are no sensor array, the recent trend is to rank them as EN since they solve

similar tasks. Furthermore, above mentioned techniques allow to minimize the sample handling procedures in many practically essential cases.

The further development of "virtual" sensor concept depends on the miniaturization of an equipment specific for time-proven analytical techniques for successful implementation of the technology in handheld devices for in field applications.

One of the indicative examples is mass spectrometry utilizing desorption electrospray ionization techniques as an ambient method for liquid-extraction surface sampling. Desorption electrospray ionization is carried out by directing electrosprayed charged droplets and ions of solvent onto the surface to be analyzed. The impact of the charged particles on the surface produces gaseous ions of material originally present on the surface. The resulting mass spectra are similar to normal mass spectra in that they show mainly singly or multiply charged molecular ions of the analytes [140-142]. 


\section{Concluding remarks}

Despite of intensive development of "alarm" systems based on specific sensors reacting to certain biohazard, chemical or other dangers, EN concept remains one of the more prominent for practical application owing to potentially "universal" nature of the concept. However, at present the EN technology, despite its rather long history of development, is still predominantly laboratory based, with a rather limited area of practical use. The universality of EN means that it (i) has to be able to operate in the field, in the presence of a background of many smells of different nature; (ii) has to provide an adequate analysis of objects of different nature with wide range of physical-chemical properties. One of the main barriers for the implementation of this technology is the necessity of use of sample handling procedures which are in many cases timeconsuming, expensive and require special personnel. Present day trends in this area are concerned with solving the tasks assigned to sample preparation in different ways, e.g. development of adaptive sensor arrays, applying of materials with tunable adsorption properties, advance methods of CI formation, implementation of "virtual" sensors etc. The approaches overviewed above encourage both scientist and engineers concerning developing in the near future efficient and compact EN based analytical instrumentation highly appreciated at the market. 


\section{References}

1. S. Rahman, T. Usmani, S. H. Saeed, "Review of electronic nose and applications, International journal of computing and corporate research 3, 2 (2013) SSN2249054XV3I2M2-03201.

2. A. D. Wilson, M. Baietto, Application and advances in electronic-nose technologies, Sensors 9 (2009), 5099-5148.

3. F. Röck, N. Barsan, U. Weimar, Electronic Nose: Current Status and Future Trends, Chem. Rev. 108 (2008) 705-725.

4. A. Loutfi, S. Coradeschi, G. K. Mani, P. Shankar, J. B. B. Rayappan, Electronic noses for food quality: A review, J. Food Eng. 144 (2015) 103-111.

5. S. Ampuero, J.O. Bosset, The electronic nose applied to dairy products: a review, Sensor Actuat. B-Chem, 94 (2003) 1-12.

6. J. Yinon, Detection of Explosives by Electronic Noses Anal. Chem., 75, 5 (2003) 98 A$105 \mathrm{~A}$.

7. A. D. Wilson Review of Electronic-nose Technologies and Algorithms to Detect Hazardous Chemicals in the environment, Procedia Technology 1 (2012) 453 - 463.

8. T. C. Pearce, S. S. Schiffman, H.T. Nagle, J. W. Gardner, Handbook of machine olfaction: electronic nose technology, John Wiley \& Sons, 2006.

9. S. Deshmukh, R. Bandyopadhyay, N. Bhattacharyya, R.A. Pandey, A. Jana, Application of electronic nose for industrial odors and gaseous emissions measurement and monitoring - an overview, Talanta 144 (2015) 329-340.

10. K. Arshak, E. Moore, G.M. Lyons, J. Harris, S. Clifford, A review of gas sensors employed in electronic nose applications Sensor Rev. 24, 2 (2004) 181-198.

11. B. Adhikari, S. Majumdar, Polymers in sensor applications, Prog. Polym. Sci. 29, 7 (2004) 699-766.

12. T. C. Pearce, Computational parallels between the biological olfactory pathway and its analogueThe Electronic Nose': Part II. Sensor-based machine olfaction, Biosystems 41, 2 (1997) 69-90.

13. S. Roussel, G. Forsberg, V. Steinmetz, P. Grenier, V. Bellon-Maurel, Optimisation of electronic nose measurements. Part I: metodology of output feature selection, J. food eng. 37 (1998) 207-222.

14. S. Roussel, G. Forsberg, P. Grenier, V. Bellon-Maurel, Optimisation of electronic nose measurements. Part II: Influence of experimental parameters, J. food eng. 39 (1999) 9 15.

15. S. Deutsch, Models of the Nervous System, Wiley, New York, 1967. 
16. K. Persaud, G. Dodd, Analysis of discrimination mechanisms in the mammalian olfactory system using a model nose, Nature 299 (1982) 352-355.

17. J.W. Gardner, P. Bartlett, A brief history of electronic noses Sensor. Actuat. B-Chem. 1819 (1994) 211-220.

18. J.W. Gardner, P. N. Bartlett, Electronic noses: principles and applications, New York: Oxford University Press, 1999.

19. K. H. Esbensen, C. Wagner, Theory of sampling (TOS) versus measurement uncertainty (MU) - A call for integration, Trends Anal. Chem. 57 (2014) 93-106.

20. P. Boeker, On 'Electronic Nose' methodology, Sensor. Actuat. B-Chem. 204 (2014) 2-17.

21. W. Göpel, Chemical imaging: I. Concepts and visions for electronic and bioelectronic noses, Sensor. Actuat. B-Chem. - 52 (1998) 125-142.

22. W. Göpel, U. Weimar, Chemical imaging: II. Trends in practical multiparameter sensor systems, Sensor. Actuat. B-Chem. 52 (1998) 143-161.

23. B.A. Snopok, I.V. Kruglenko, Multisensor systems for chemical analysis: state-of-the-art in Electronic Nose technology and new trends in machine olfaction, Thin Solid Films 418,1 (2002) 21-41.

24. D. Hodgins, The electronic nose: Sensor array-based instruments that emulate the human nose. Techniques for Analyzing Food Aroma, in R. Marsili (Ed.), Marcel Dekker Inc., New York, 1997, pp. 331-371.

25. P. Mielle, Electronic noses: Towards the objective instrumental characterization of food aroma, Trends Food Sci. Technol., 7 (1996) 432-438.

26. P. Mielle, F. Marquis, An alternative way to improve the sensitivity of electronic olfactometers, Sensor. Actuat. B-Chem. 58 (1999) 526-535.

27. L. A. Jurado, J. E. Ream, Methods and systems for differentiating of soybeans, United States patent US 8,640,525 B2, 2014.

28. P. Boltovets, Yu. Schwarts, B. Snopok, Intellectual system of the corn quality control: Perspectives and applications, Visnyk Lviv Univ. Ser. Physics 44, (2009)172-177(in Ukrainian).

29. B.A. Snopok, Intelligent sensor systems based on the cross-reactive arrays of chemical sensors, Science and Innovation 6(5) (2010) 65-71 (in Ukrainian).

30. N. Bhattacharya, B. Tudu, A. Jana, D. Ghosh, R. Bandhopadhyaya, A. B. Saha, Illumination heating and physical raking for increasing sensitivity of electronic nose measurements with black tea, Sensor. Actuat. B-Chem. 131 (2008) 37-42.

31. Patrick Mielle, Marie Souchaud, Pascale Landy, Elisabeth Guichard, A direct thermal 
desorber as a sampling device for application specific sensor system, Sensor. Actuat. BChem. 116 (2006) 161-167.

32. A. Massacane, J. Vorobioff, K. Pierpauli, N. G. Boggioa, S. Reich, C. A. Rinaldi, A. Boselli, A. Lamagna, M. L. Azcárate, J. Codnia, F. Manzano, Increasing electronic nose recognition ability by sample laser irradiation, Sensor. Actuat. B-Chem. 146 (2010) 534538.

33. A. Sides, K. Robards, S. Helliwel, Developments in extraction techniques and their application to analysis of volatiles in foods, Trends Anal. Chem. 19, 5 (2000) 322-329.

34. Gary A. Robbins, Suya Wang, James D. Stuart Using the static headspace method to determine Henry's law constants Anal. Chem., 1993, 65 (21), pp 3113-3118

35. S. Ouoba, F. Cherblanc, J. Koulidiati, and J.-C. Bénet A New Experimental Method to Determine the Henry's Law Constant of a Volatile Organic Compound Adsorbed in Soil Journal of Chemistry Volume 2015 (2015), Article ID 479327, 7 pages http://dx.doi.org/10.1155/2015/479327

36. I. Kruglenko, Yu. Shirshov, J. Burlachenko, A. Savchenko, S. Kravchenko, M.G. Manera, R. Rella, Sensitive coating for water vapors detection based on thermally sputtered calcein thin films, Talanta, 824 (2010) 1392-1396.

37. J.A. Guadarrama, J.A. Fernandez, M. Iniguez, J. Souto, J.A. De Saja, Array of conducting polymers sensors for the characterisation of wines, Anal. Chim. Acta 411 (2000) 193200.

38. I. Kruglenko, J. Burlachenko, S. Kravchenko, A. Savchenko, M. Slabkovska, Yu. Shirshov, Adsorption properties of thermally sputtered calcein film, Applied Surface Science 301 ( 2014) 378-382

39. M. Castro, B. Kumar, J.F. Feller, Z. Haddi, A. Amari, B. Bouchikhi, Novel e-nose for the discrimination of volatile organic biomarkers with an array of carbon nanotubes (CNT) conductive polymer nanocomposites (CPC) sensors Sensor. Actuat. B-Chem. 159 (2011) $213-219$.

40. I.V. Kruglenko, B.A. Snopok, Yu. Shirshov, F.J.Rowell Multisensor systems for gas analysis: optimization of arrays for classification of pharmaceutical products, Semiconductor Physics, Quantum Electronics \& Optoelectronics, 7, 2 (2004) 207-216.

41. Patrick Mielle, Florence Marquis, An alternative way to improve the sensitivity of electronic olfactometers, Sensor. Actuat. B-Chem. 58 (1999) 526-535.

42. S. Ampuero, J.O. Bosset, The electronic nose applied to dairy products: a review, Sensor. Actuat. B-Chem. 94 (2003) 1-12.

43. M. Peris, L. Escuder-Gilabert, A 21 st century technique for food control: Electronic 
noses, Anal. Chim. Acta 638 (2009) 1-15.

44. E. Schaller, J. O. Bosset, F. Escher, 'Electronic Noses' and Their Application to Food, Lebensm.-Wiss. u.-Technol., 31 (1998) 305-316.

45. H. Knobloch, C. Turner, A. Spooner, M. Chambers, Methodological variation in headspace analysis of liquid samples using electronic nose, Sensor. Actuat. B-Chem. 139 (2009) 353-360.

46. Yu.V. Burlachenko, B.A. Snopok, Multisensor arrays for gas analysis based on photosensitive organic materials: An increase in the discriminating capacity under selective illumination conditions, Journal of Analytical Chemistry 63, 6 (2008) 610-619.

47. C. Dufour, W. Ezzedine, E. Debeuf, Sampling method for use in odor measurement, United States Patent Application 20130263644, Kind Code A1, 2013.

48. N. Orgovan, D. Patko, C. Hos, S. Kurunczi, B. Szabó, J. J. Ramsden, R. Horvath, Sample handling in surface sensitive chemical and biological sensing: A practical review of basic fluidics and analyte transport, Adv. Colloid Interfac 211 (2014) 1-16.

49. G. N. Tchoupo, A. Guiseppi-Elie, On pattern recognition dependency of desorption heat, activation energy, and temperature of polymer-based VOC sensors for the electronic NOSE, Sensor. Actuat. B-Chem. 110 (2005) 81-88.

50. L. Alwis, T. Sun, K.T.V. Grattan, Optical fibre-based sensor technology for humid-ity and moisture measurement: review of recent progress, Measurement 46(10) (2013) 40524074.

51. David James, Simon M. Scott, Zulfiqur Ali, William T. O'Hare Chemical Sensors for Electronic Nose Systems Microchim. Acta 149, 1-17 (2005).

52. I. Kruglenko, J. Burlachenko, S. Kravchenko, P. Lytvyn, E. Manoilov, M. Slabkovska Calcein and calcein-Ag films under vapor exposure: Sensing properties and reversible film restructuring, Talanta 101 (2012) 267-272.

53. B. Snopok, I. Kruglenko, Analyte induced water adsorbability in gas phase biosensors: the influence of ethinylestradiol on the water binding protein capacity, Analyst 140

54. I.V. Kruglenko, B.A. Snopok, Cleaning Procedure based on Displacement Reactions: Application to the Electronic Nose technology, abstract book of ISOEN (2003), Riga, 212-215.

55. M. Ghasemi-Varnamkhasti, S.S. Mohtasebi, z.L. Rodriguez-Mendez, J. Lozano, S.H. Razavi, H. Ahmadi, Potential application of electronic nose technology in brewery, Trends in Food Sci. Tech., 22, 4 (2011) 165-174.

56. Z. Yang, F. Dong, K. Shimizu, T. Kinoshita, M. Kanamori, A. Morita, N. Watanabe, Identification of coumarin-enriched Japanese green teas and their particular flavor using 
electronic nose, J. Food Eng. 92 (2009) 312-316.

57. S. M. Cho, Y. J. Kim, G. S. Heo, S.-M. Shin, Two-step preconcentration for analysis of exhaled gas of human breath with electronic nose, Sensor. Actuat. B-Chem. 117 (2006) $50-57$.

58. CG. Zambonin, Coupling solid-phase micro-extraction to liquid chromatography. A review, Anal Bioanal Chem 375 (2003) 73-80.

59. H. Kataoka, Automated sample preparation using in-tube solid-phase microextraction and its application - a review, Anal Bioanal. Chem. 373 (2002) 31-45.

60. E. Stashenko, J. Martínez, Derivatization and solid-phase microextraction, Trends Anal Chem 23 (2004) 553-561.

61. B. Zygmunt, A. Jastrzebska, J. Namiesnik, Solid phase microextraction - a convenient tool for the determination of organic pollutants in environmental matrices, Crit Rev Anal Chem 31 (2001) 1-18.

62. H. Kataoka, S. Narimatsu, HL. Lord, J. Pawliszyn, Development of on-line in-tube solidphase microextraction/LC/MS system (Focussing Review), Chromatography 20 (1999) $237-46$.

63. E. E. Stashenko, J. R. Martínez, Sampling volatile compounds from natural products with headspace/solid-phase micro-extraction, J. Biochem. Biophys. Methods 70 (2007) 235 242.

64. J. Lozano, J. P. Santos, M. C. Horrillo, Enrichment sampling methods for wine discrimination with gas sensors, J. Food Compos. Anal., 21 (2008) 716-723.

65. C. Dietz, J. Sanz, C. Cámara, Recent developments in solid-phase micro-extraction coatings and related techniques, J Chromatogr A 1103(2006) 183 -92.

66. Jingcun $\mathrm{Wu}$, Janusz Pawliszyn Preparation and applications of polypyrrole films in solidphase microextraction Journal of Chromatography A, 909 (2001) 37-52.

67. H. Kataoka, L. Heather, J. Pawliszyn, Applications of solid-phase micro-extraction in food analysis, J Chromatogr A 880 (2000) $35-62$.

68. J. G. Wilkes, E. D. Conte, Y. Kim, M. Holcomb, J. B. Sutherland, D. W. Miller, Sample preparation for the analysis of flavors and off-flavors in foods. J Chromatogr A 880 (2000) 3-33.

69. L. Pillonel, J.O. Bosset, R. Tabacchi, Rapid preconcentration and enrichment techniques for the analysis of food volatile. A review, Lebensm-Wiss Technol Food Sci, 35 (2002) $1-14$.

70. M. Vinaixa, A. Vergara, C. Duran, E. Llobet, C. Badia, J. Brezmes, X. Vilanova, X. Correig, Fast detection of rancidity in potato crisps using e-noses based on mass 
spectrometry or gas sensors, Sensor. Actuat. B-Chem. 106 (2005) 67-75.

71. N. Bari'e, M. Bücking, M. Rapp, A novel electronic nose based on miniaturized SAW sensor arrays coupled with SPME enhanced headspace-analysis and its use for rapid determination of volatile organic compounds in food quality monitoring, Sensor. Actuat. B-Chem. 114 (2006) 482-488.

72. A. Cimato, D. Dello Monaco, C. Distante, M. Epifani, P. Siciliano, A. M. Taurino, M. Zuppa, G. Sani, Analysis of single-cultivar extra virgin olive oils by means of an Electronic Nose and HS/SPME/GC/MS methods. Sensor. Actuat. B-Chem. 114 (2006) 674-80.

73. A. Guadarrama, J.A. Fernandez, M. Iniguez, J. Souto, J.A. de Saja, Discrimination of wine aroma using an array of conducting polymer sensors in conjunction with solid-phase micro-extraction (SPME) technique, Sensor. Actuat. B-Chem. 77 (2001) 401-408.

74. F. Augusto, A. L. P. Valente, Applications of solid-phase microextraction to chemical analysis of live biological samples, Trends Anal. Chem. 21, 6+7 (2002) 428-438.

75. M. de F. Alpendurada, Solid-phase microextraction: a promising technique for sample preparation in environmental analysis, J Chromatogr A 889 (2000) 3-14.

76. J. Dewulf, T. Huybrechts, H. Van Langenhove, Developments in the analysis of volatile halogenated compounds. Trends Anal Chem 25 (2006) 300 -309.

77. K. G. Furton, J. R. Almirall, M. Bi, J. Wang, L. Wu, Application of solid-phase microextraction to the recovery of explosives and ignitable liquid residues from forensic specimens, J Chromatogr A 885 (2000) 419 -32.

78. M. Garc'1a, M.C. Horrillo, J.P. Santos, M. Aleixandre, I. Sayago, M.J. Fernández, L. Arés, J. Gutiérrez, Artificial olfactory system for the classification of Iberian hams, Sensor. Actuat. B-Chem. 96 (2003) 621-629.

79. J. Lozano, J.P. Santos, J. Guti'errez, M.C. Horrillo, Comparative study of sampling systems combined with gas sensors for wine discrimination, Sensor. Actuat. B-Chem. 126 (2007) 616-623.

80. J. P. Santos, J. Lozano, M. Aleixandre, T. Arroyo, J. M. Cabellos, M. Gil, M. del C. Horrillo, Threshold detection of aromatic compounds in wine with an electronic nose and a human sensory panel, Talanta 80 (2010) 1899-1906.

81. T. C. Pearce, Computational parallels between the biological olfactory pathway and its analogue ‘The Electronic Nose': Part I. Biological olfaction, Biosystems 41, 1 (1997) 4367.

82. F.K. Che Harun, J.A. Covington, J.W. Gardner, Mimicking the biological olfactory system: a Portable electronic Mucosa, IET Nanobiotechnol. 6, 2 (2011) 45-51. 
83. J. W. Gardner, J. E. Taylor, Novel Convolution-Based Signal Processing Techniques for an Artificial Olfactory Mucosa IEEE Sensors Journal 9 (2009) 929 - 935.

84. A.P. Filippov, P.E. Strizhak, T.G. Serebry, Studies of the Adsorption of Organic Vapours by Metal Stearates and their Complexes with Octadecylamine in a Flow Impulse Regime by Piezoquartz Sensor Techniques, Adsorption Science and Technology. 26 (2008) 15.

85. R.C. McKellar, HP V. Rupasinghe, X. Lu, K. P. Knight, The electronic nose as a tool for the classification of fruit and grape wines from different Ontario wineries, J.Sci. Food Ag. 85 (2005). 2391-2396.

86. A. Z. Berna, S. Trowell, D. Clifford, W. Cynkar, D. Cozzolino, Geographical origin of Sauvignon Blanc wines predicted by mass spectrometry and metal oxide based electronic nose, Anal. Chim. Acta 648 (2009) 146-152.

87. J.R. Stetter, S. Strathmann, C. McEntegart, M. Decastro, W.R. Penrose New sensor arrays and sampling systems for a modular electronic nose, Sensor. Actuat. B-Chem. 69 (2000) 410-419.

88. C. Pinheiro, C. M. Rodrigues, T. Schafer, J. G. Crespo, Monitoring the aroma production during wine-must fermentation with an electronic nose, Biotechnol Bioeng. 77, 6 (2002) 632-40.

89. I.V. Kruglenko, B.A. Snopok, Intelligent Sensing Based on Combination of "Hard" and "Soft" Nanomaterials: Application to the Electronic Nose Technology, Proceedings of The Ninth International Symposium on Olfaction and Electronic Nose (Ed. Arnaldo D’Amico and C.Di Natale), MMIII Aracne Editrice S.r.1., P.104-111 (2003).

90. I.Kruglenko, Yu. Shirshov, Effect of molecular sieves on discrimination efficiency of a multisensor gas-analysis system. Semiconductor Physics, Quantum Electronics and Optoelectronics, 11, 2 (2008) 141-148.

91. J.Z. Liu, Gas chromatograph and quartz crystal microbalance sensor apparatus, United States Patent Application Publication, No US 2006/0179918 A1, Aug. 17, (2006).

92. A.P. Filippov, P.E.Strizhak, T.G. Serebrij, B.A. Snopok, Analytical approach for the analysis of single and complex mixtures of volatile compound and equipment for this analysis, Patent of Ukraine №47450 (10.02.2010).

93. T. M. Dymerski, T. M. Chmiel, and W. Wardencki, An odor-sensing system-powerful technique for foodstuff studies, Rev. Sci. Instrum. 82 (2011) 111101.

94. Q. Zhong, W.H.Steinecker, E.T.Zellers, Characterization of a high-performance portable GC with a chemiresistor array detector, Analyst. 134 (2009) 283-293.

95. P. Chang, J.-S. Shih, Multi-channel piezoelectric quartz crystal sensor for organic vapours, Analytica Chimica Acta 403 (2000) 39-48. 
96. A.P. Filippov, P.E. Strizhak, T.G. Serebry, A.I. Tripolsky, B.A. Snopok, V.O. Khavrus, T.S. Ivashchenko, Dual analytical system based on multichannel array and gas chromatograph for the identification of volatile organic compounds, Ukrainian journal of chemistry 73(1-2) (2007) 97-101.

97. I. Heberle, A. Liebminger, U. Weimar, W. G*opel, Optimised sensor arrays with chromatographic preseperation: characterisation of alcoholic beverages, Sensor. Actuact. B-Chem. 68 (2000) 53-57.

98. A. K. Wanekaya, M. Uematsu, M. Breimer, O. A. Sadik, Multicomponent analysis of alcohol vapors using integrated gas chromatography with sensor arrays, Sensor. Actuat. B-Chem. 110 (2005) 41-48.

99. A.P. Filippov, P.E. Strizhak, T.G. Serebry, A.I. Tripolsky, B.A. Snopok, V.O. Khavrus, T.S. Ivashchenko, New Materials of Coatings for Discrimination of Hydrocarbons by Multisensor System Combined with Gas Chromatograph, Theor. Exp. Chemmistry 41, 6 (2005) 371-376.

100. A.P. Filippov, P.E. Strizhak, T.G. Serebry, B.A. Snopok, Direct Identification of Volatile Organic Vapors in Complex Mixtures: Advanced Chemical Imaging of Analytes by Cross-Reactive Sensor Arrays with Temporal Separation, Sens. Lett. 12, 8 (2014) 12591266.

101. I.V. Gavrilyuk, B.A. Snopok, E.P. Matsas, Yu.M. Shirshov, E.F. Venger, Chemical sensing based on multiway analysis: temporal chemical images of complex mixtures, Abstract book of $8^{\text {th }}$ international meeting on chemical sensors, Basel, Switzerland, (2-5 July 2000) 493.

102. C. L. Morgan, D. J. Newman, J. M. Burrin C. P. Price, The matrix effects on kinetic rate constants of antibody-antigen interactions reflect solvent J. Immunol. Methods. 217(1-2) (1998) 51-60.

103. S. Armstrong, Z-F Miao, F. J. Rowell, Z. Ali Simple dip strip ELISA for airborne estrogenic steroids, Analytica chimica acta 444, 1 (2001) 79-86.

104. D. C. Wedge, A. Das, R. Dost, J. Kettle, M.-B. Madec, J. J. Morrison, M. Grell, D. B. Kell, T. H. Richardson, S. Yeates, M. L. Turner, Real-time vapour sensing using an OFET-based electronic nose and genetic programming, Sensor. Actuat. B-Chem. 143, 1, (2009) 365-372.

105. J. Nieß, T. Hamacher, P. S. Lammers, E.Weber, P. Boeker, A miniaturized thermal desorption unit for chemical sensing below odor threshold, Sensor. Actuat. B- Chem. 95, $1-3,(2003) 1-5$.

106. S. Armenta, M. Alcala, M. Blanco, A review of recent, unconventional applications of ion 
mobility spectrometry (IMS), Analytica Chimica Acta 703, 2 (2011) 114-123.

107. Tsung-Kuan A. Chou, Li-Peng Wang, Chia-Jung Lu, Shih-Chi Chu, Chien-Lin Huang, Gas collection and analysis system with front-end and back-end pre-concentrators and moisture removal, US Patent US 8,707,760 B2, Apr. 29, 2014.

108. Li-Peng Wang, Chien-Lin Huang, Tsung-Kuan A. Chou Handled gas analysis systems for point-of-care medical applications US Patent US 8,695,401 B2, Apr. 15, 2014.

109. L. A. Jurado, J.E. Ream Methods and systems for differentiating of soybeans US Patent US 8,640,525 B2, Feb. 4, 2014.

110. A. T. Jones, Jr. Apparatus and method of contaminant detection for food industry US Patent US 8,272,280 B2, Sep. 25, 2012.

111. Z. Yongming, W. Xiaowei, F. Jun, w. Jinjun, Enclosed space fire hazard detection alarm system and alarm method based on electronic nose technology, CN2013126143 20130121, 2013-05-22.

112. http://www.teledynetekmar.com/

113. www.airsense.com

114. X. Hong, J. Wang, Z. Hai, Discrimination and prediction of multiple beef freshness indexes based on electronic nose, Sensor. Actuat. B-Chem. 161 (2012) 381-389.

115. http://www.gerstel.com

116. H. Ge, J. Liu, Identification of gas mixtures by a distributed support vector machine network and wavelet decomposition from temperature modulated semiconductor gas sensor Sensor. Actuat. B-Chem. 117, 2 (2006) 408-414.

117. A. Gramm, A. Schütze, High performance solvent vapor identification with a two sensor array using temperature cycling and pattern classification, Sensor. Actuat. B-Chem. 95, 13 (2003) 58-65.

118. A. P. Lee, B. J. Reedy, Temperature modulation in semiconductor gas sensing, Sensor. Actuat. B-Chem. 60, 1 (1999) 35-42.

119. K. A. Ngo, P. Lauque, K. Aguir, High performance of a gas identification system using sensor array and temperature modulation, Sensor. Actuat. B-Chem. 124, 1 (2007) 209216.

120. B. Raman, D. C. Meier, J. K. Evju, S. Semancik, Designing and optimizing microsensor arrays for recognizing chemical hazards in complex environments, Sensor. Actuat. BChem. 137 (2009) 617-629.

121. E. Comini, A. Cristalli, G.Fagila, G. Sberveglieri, Light enhanced gas sensing properties of indium oxide and tin dioxide sensors, Sensor. Actuat. B-Chem. 65 (2000) 260 - 263.

122. R. Bajpaia, A. Motayed, A.V. Davydov, V.P. Oleshko, G.S. Aluri, K.A. Bertnesse, M.V. 
Rao, M.E. Zaghloula, UV-assisted alcohol sensing using $\mathrm{SnO} 2$ functionalized GaN nanowire devices, Sensor Actuat. B-Chem. 171-172 (2012) 499-507.

123. I. Castro-Hurtado, G.G. Mandayo, E. Castaño, Conductometric formaldehyde gas sensors. A review: From conventional films to nanostructured materials, Thin Solid Films 548 (2013) 665-676.

124. J. Burlachenko, B. Snopok Controlling of the adsorption-desorption processes on the surface of chemical sensors coated by photosensitive pththalocyanine films, Optoelectronics and Semiconductor Techniques, 40 (2005) 136-142.

125. I.V. Kruglenko, E. G. Manoilov, B. A. Snopok, Influence of complex macromolecules on the luminescence properties of organic surface structures, abstract book of "Physical methods in biology, ecology and medicine" Shatsk, Ukraine (2011) 57-59.

126. F. M. Lopez, Inkjet-Printed Multisensor Platform on Flexible Substrates for Environmental Monitoring, Ecole Polytechnique Federale de Lasagna, 2014.

127. D. W. Hatchett, M. Josowicz, Composites of Intrinsically Conducting Polymers as Sensing Nanomaterials, Chem. Rev. 108 (2) (2008) 746-769.

128. Y. Park, D. Shin, Y. N. Jang, Ah-Hyung A. Park, CO2 Capture Capacity and Swelling Measurements of Liquid-like Nanoparticle Organic Hybrid Materials via Attenuated Total Reflectance Fourier Transform Infrared Spectroscopy, J. Chem. Eng. Data, 57 (1) (2012) 40-45.

129. E. A. Guliants, R. Schwarb, H. Bearbower, J.ames R. Gord, Ch. E. Bunker, Functional nanoparticles in thin films as sensing media, Rev. Adv. Mater.Sci. 10 (2005) 289-294.

130. U. Latif, S. Can, O. Hayden, P. Grillberger, F. L. Dickert, Sauerbrey and anti-Sauerbrey behavioral studies in QCM sensors-Detection of bioanalytes, Sensor. Actuat. BChem.176 (2013) 825-830.

131. S. M. Notley, M. Eriksson, L. Wågberg, Visco-elastic and adhesive properties of adsorbed polyelectrolyte multilayers determined in situ with QCM-D and AFM measurements, J. Colloid Interf. Sci. 292, 1 (2005) 29-37.

132. A. Kubono, R. Akiyama, Viscoelastic Analysis in the Formation of Organic Thin Films, Mol. Cryst. Liq. Cryst. 445, 1 (2006) 213-222.

133. V. Chabot, C. M. Cuerrier, E. Escher, V. Aimez, M. Grandbois, P. G. Charette, Biosensing based on surface plasmon resonance and living cells, Biosensors and Bioelectronics, 24, 6, (2009) 1667-1673.

134. J. Burlachenko, B. Snopok, S. Capone, P. Siciliano, Performance of machine olfaction: effect of uniqueness of the initial data and information coding on the discrimination 
ability of multisensor arrays, IEEE Sensors Journal. 11, 3, (2011) 649-656.

135. I. Kruglenko, B.Snopok, Yu. Shirshov, E. Venger, Digital aroma technology for chemical sensing: temporal chemical images of complex mixtures Semiconductor Physics, Quantum Electronics and Optoelectronics 3, 4 (2000) 529-541.

136. B. Snopok, Nonexponential Kinetics of Surface Chemical Reactions, Theoretical and Experimental Chemistry 50, 2 (2014) 67-95.

137. R. Gutierrez-Osuna, H. Troy Nagle, S. S. Schiffman, Transient response analysis of an electronic nose using multi-exponential models Sensor. Actuat. B-Chem. 61 (1999) 170182.

138. A. Szczurek, M. Maciejewska, B. Flisowska-Wiercik, Method of gas mixtures discrimination based on sensor array, temporal response and data driven approach, Talanta 83, 3 (2011) 916-923.

139. V. V. Strelchuk, O. F. Kolomys, E. B. Kaganovich, I. M. Krishchenko, B. O. Gilichenko, M. I. Boyko, S. O. Kravchenko, I. V. Kruglenko, O. S. Lytvyn, E. G. Manoilov, and Iu. M. Nasieka, Optical characterization of SERS substrates based on porous Au films prepared by pulsed laser deposition, J. Nanomater. 2015 (2015) 1-7.

140. P. J. Roach, J. Laskin, A. Laskin, Nanospray desorption electrospray ionization: an ambient method for liquid-extraction surface sampling in mass spectrometry. Analyst 135 (2010) 2233-2236.

141. J. P. Willams, J. H. Scrivens, Rapid accurate mass desorption electrospray ionisation tandem of pharmaceutical samples. Rapid communication in mass spectrometry 19(24) (2005) 3643-3650.

142. Z. Takáts, J. M. Wiseman, B. Gologan, R. G. Cooks, Mass Spectrometry Sampling Under Ambient Conditions with Desorption Electrospray Ionization Science 15 Vol. 306 no. 5695 (2004) 471-473. 


\section{Figure captions}

Figure 1 - Schematic diagram of core processes of analytical workflow is illustrating the concept of e-nose platform. The keystone of the procedure is transformation of the object under consideration (emission source) into sample and then into test sample through headspace specific procedures and following transformations (enrichment, separation, etc.). In the common case the analyzed object, headspace, sample and test sample are different media in composition, concentrations (both absolute and relative) and even the aggregate state.

Figure 2 - Sample handling during the analytical workflow of EN measurement: HS formation is the most common first step of sample preparation; HS can be used for the measurement as is, in static or dynamic mode; otherwise it can be modified by enrichment or filtration/separation procedures.

Figure 3 - The realization of DHS injection: (a) - bubbling, (b) - surface evaporation and (c) droplet evaporation.

Figure 4 - Factors affecting the EN measurement process and their influence on the quality of classification.

Figure 5 - Filtration and temporal separation techniques for the EN applications: a) filtering on the example of low-pressure column; b) separation by chromatographic (high-pressure) column; c) separation with viscous liquid. 


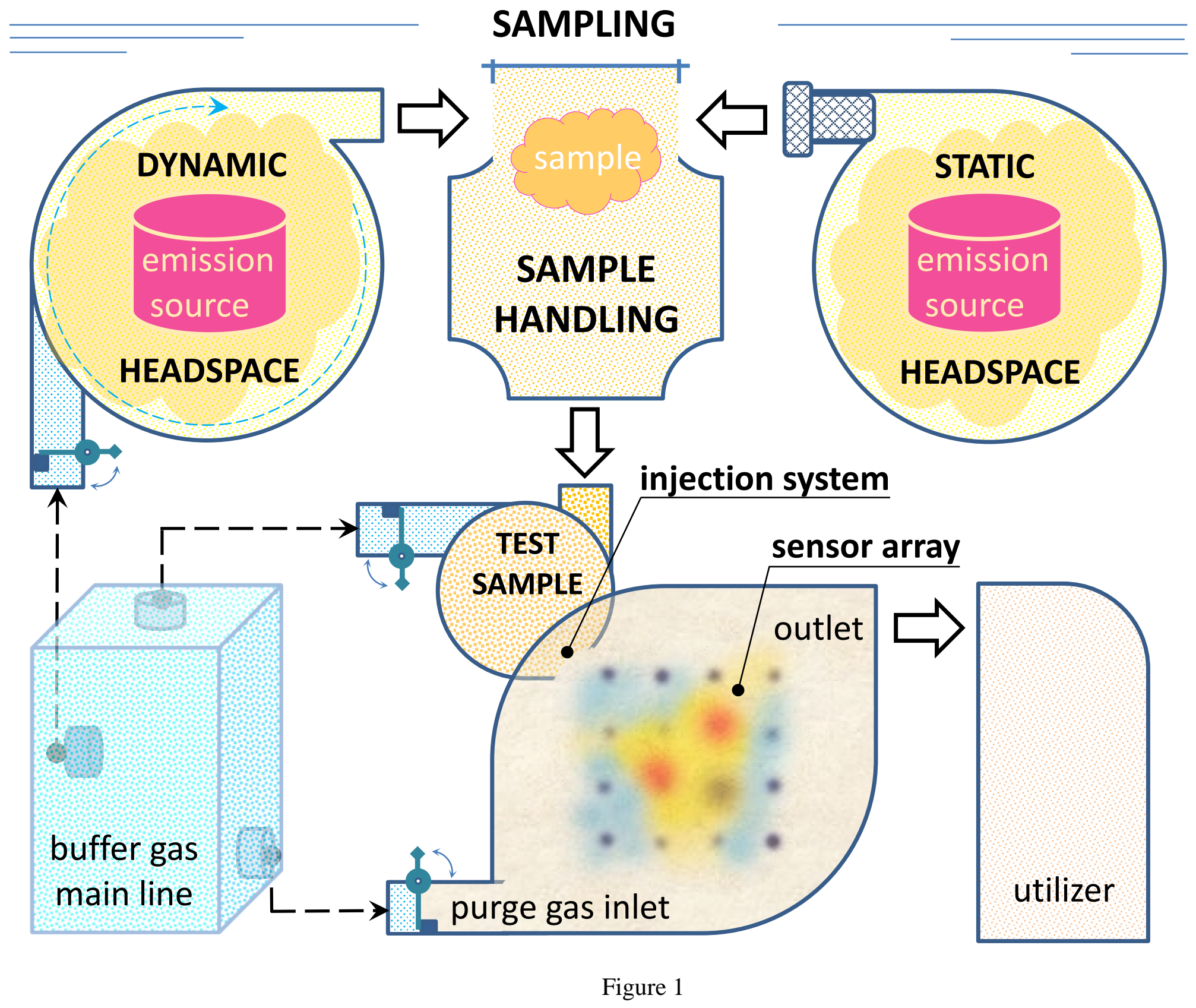




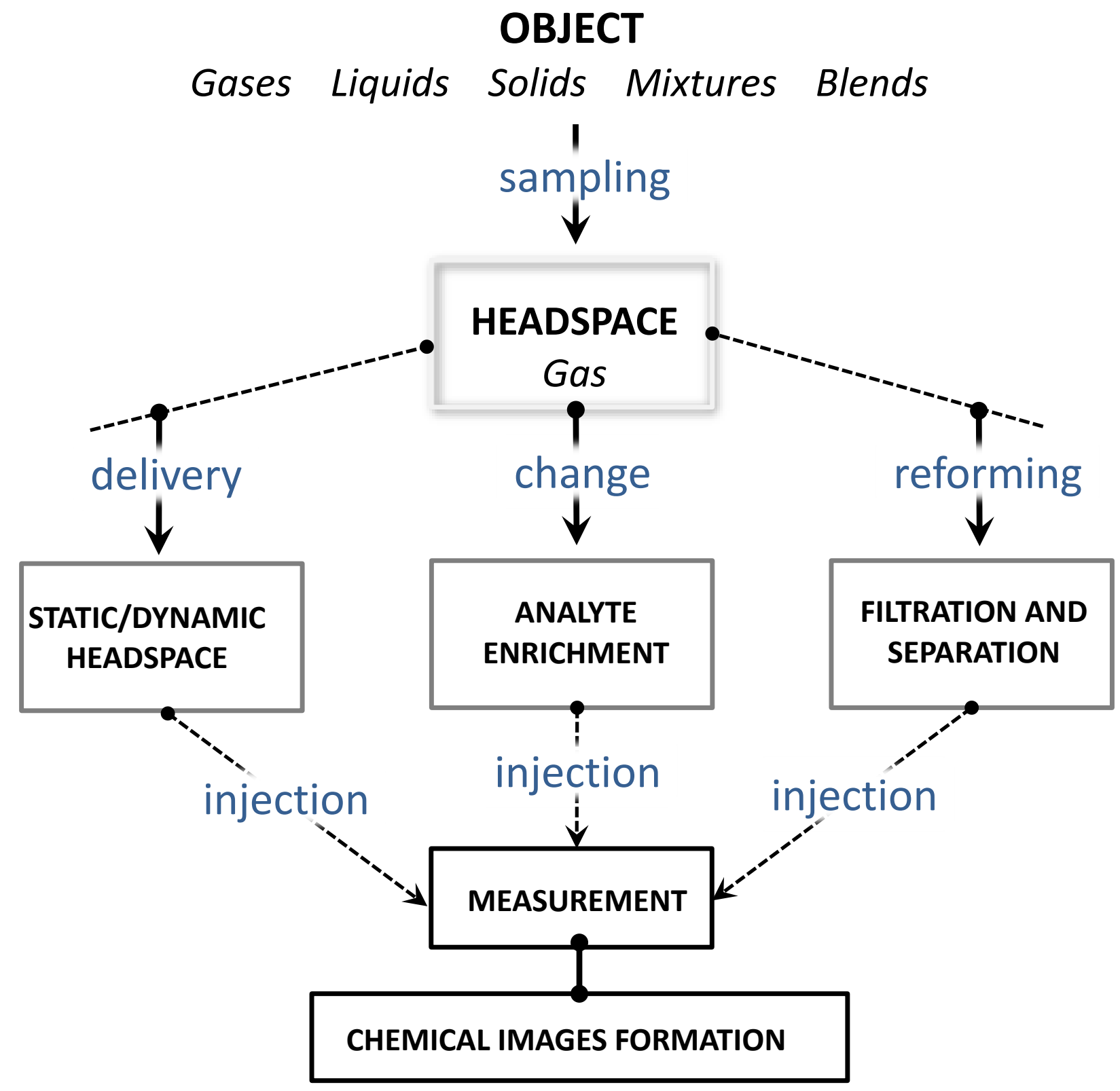

Figure 2

40 
purge gas

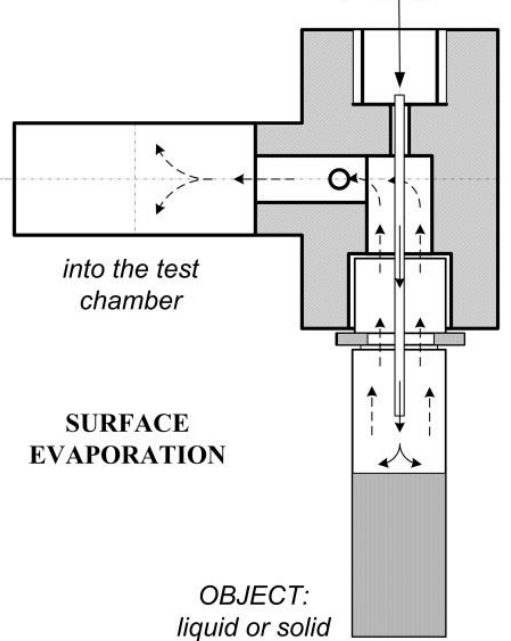

purge gas

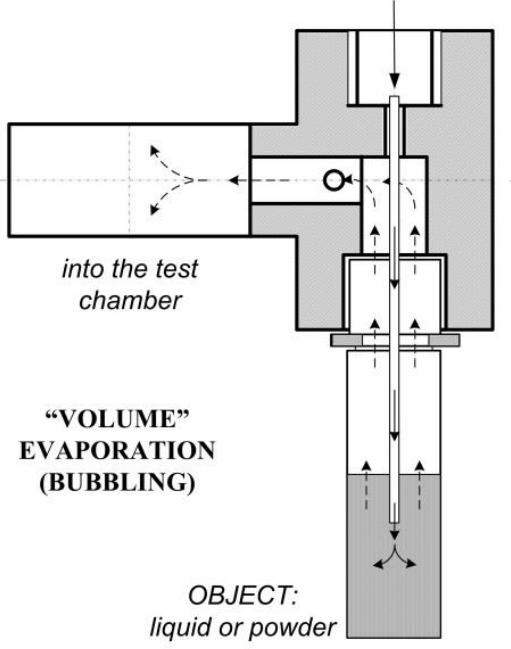

liquid or powder

Figure 3 purge gas

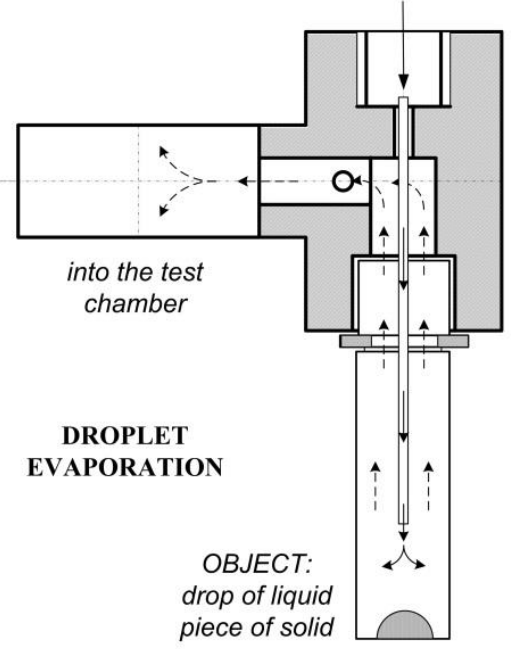




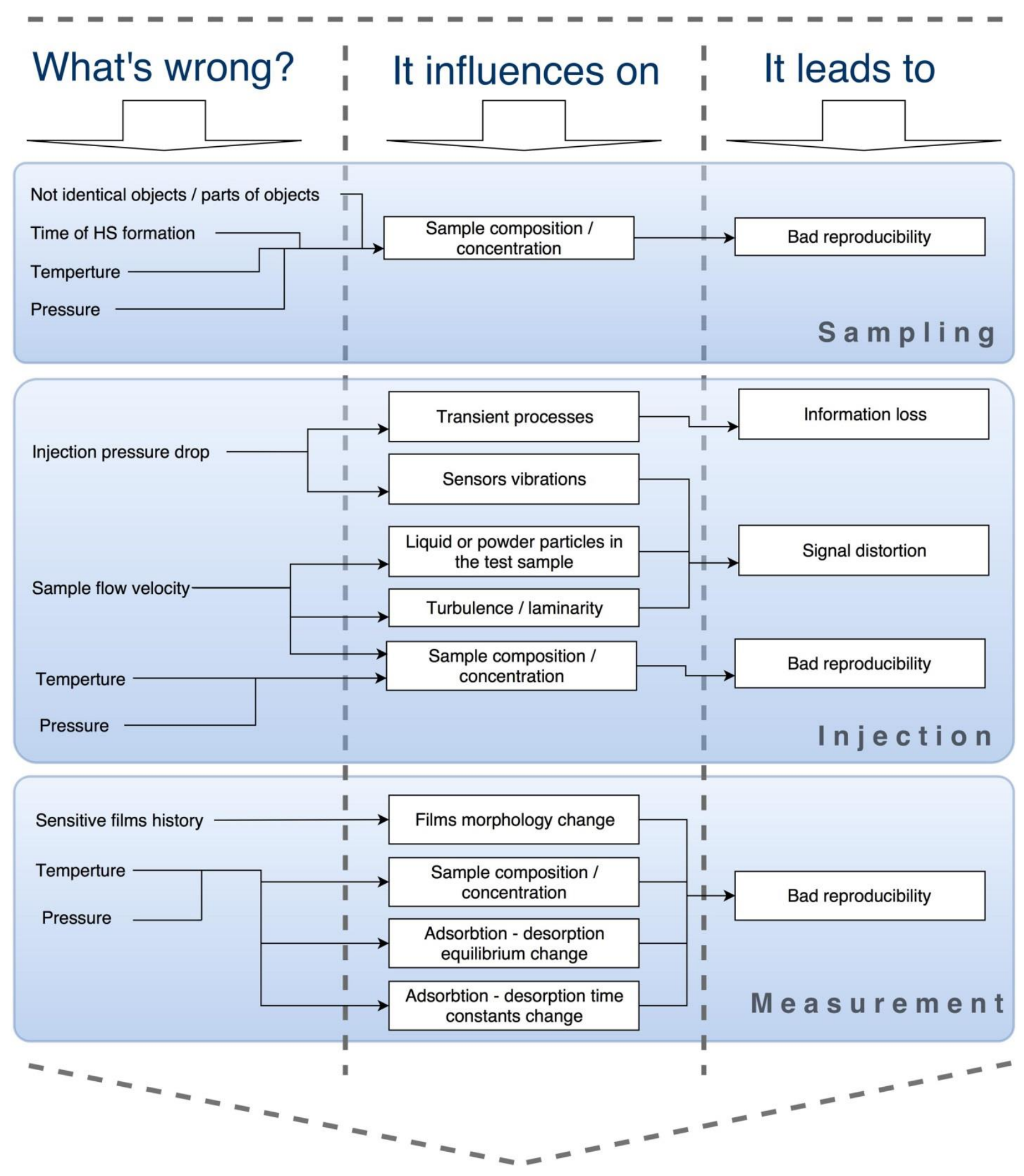

\section{Classification}

Figure 4 


\section{FILTRATION AND TEMPORAL SEPARATION TECHNIQUES}

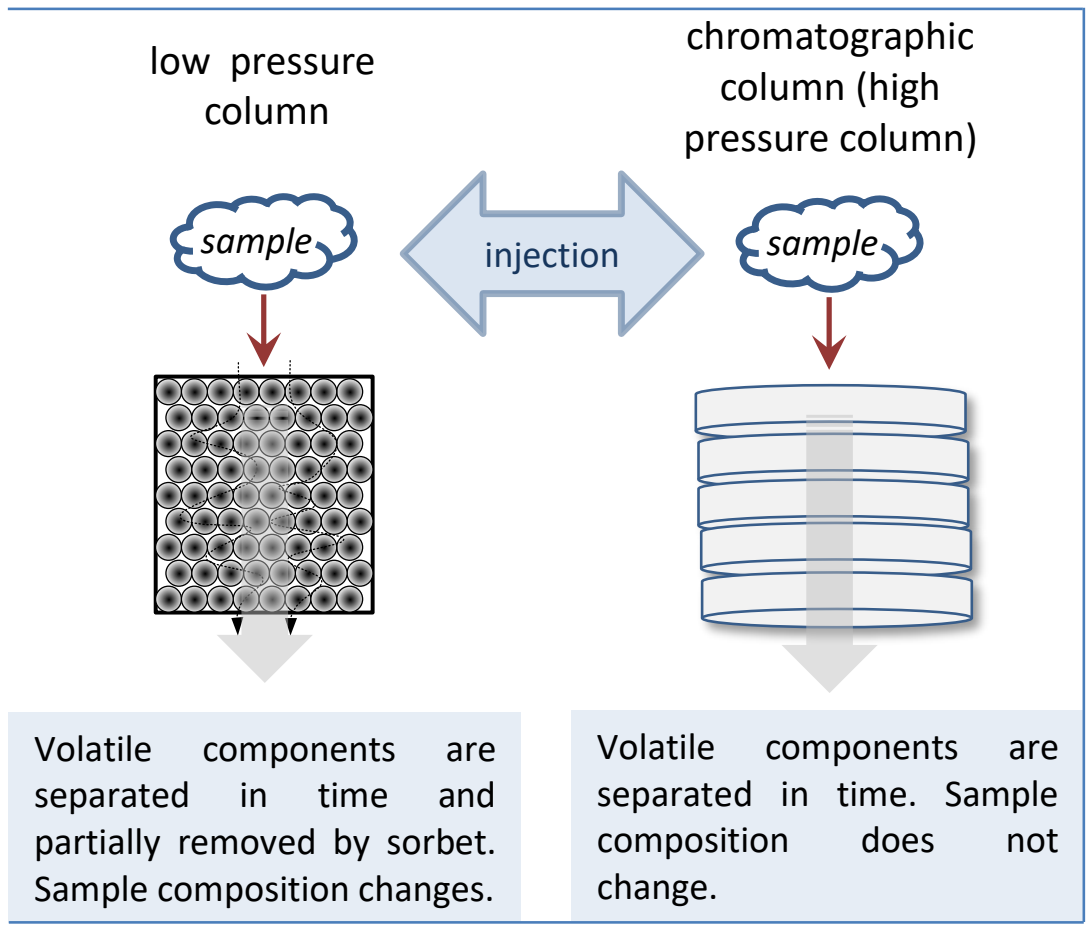

a) b)

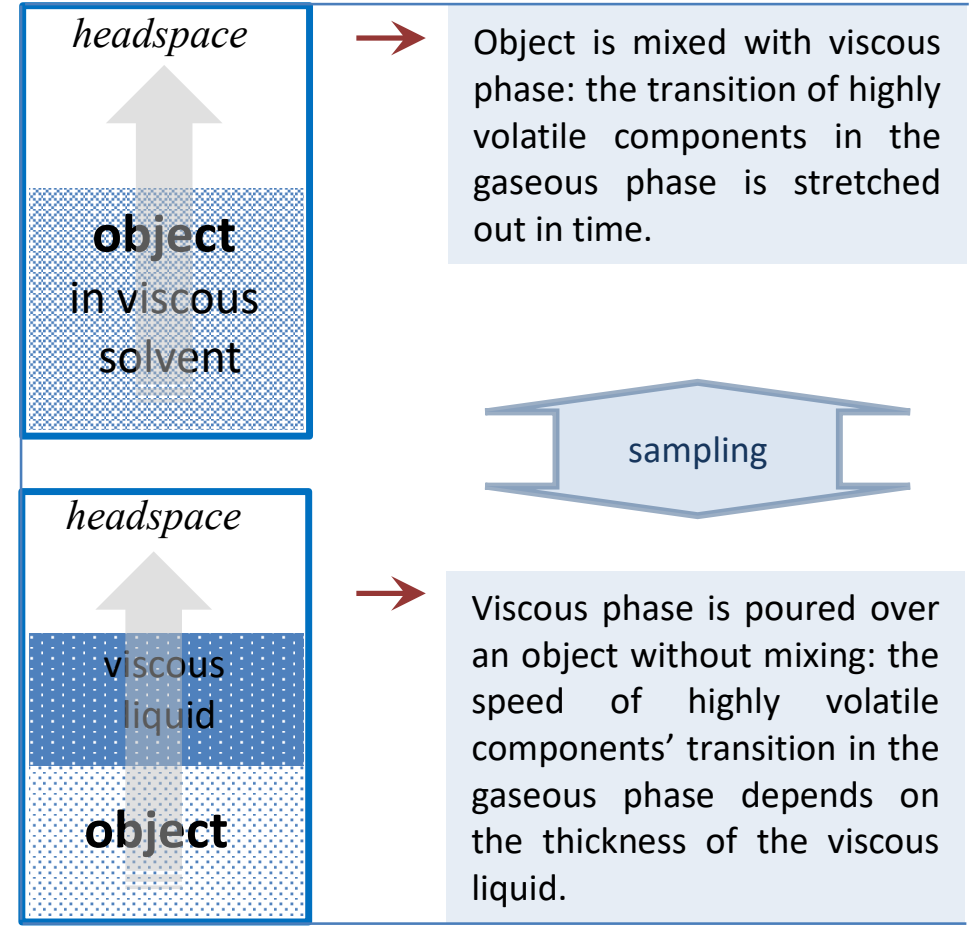

c)

Figure 5 
Table 1. Commercially available sample handling systems suitable for use in EN.

\begin{tabular}{|c|c|c|}
\hline Device / Manufacturer & Functions and application areas & Refs. \\
\hline $\begin{array}{l}\text { Versa Automated } \\
\text { Headspace Vial Sampler / } \\
\text { Teledyne Tekmar }\end{array}$ & $\begin{array}{l}\text { SHS sampler with a heater and pressure control. } \\
\text { Application areas: identification of residual solvents } \\
\text { in bulk or finished pharmaceuticals; contaminants } \\
\text { in packaging materials; volatile organic compounds } \\
\text { in drinking water, wastewater, and soils. }\end{array}$ & [110] \\
\hline $\begin{array}{l}\text { HT3 }{ }^{\text {TM }} \text { Static and } \\
\text { Dynamic Headspace } \\
\text { Analyzer / Teledyne } \\
\text { Tekmar }\end{array}$ & $\begin{array}{l}\text { Contains autosampler, SHS, DHS, sorbent trap. Has } \\
\text { a heater and pressure control. } \\
\text { Application areas: pharmaceutical; flavor, } \\
\text { fragrance; packaging; petrochemical; blood alcohol } \\
\text { and forensic toxicology; polymers; environmental. }\end{array}$ & {$[111]$} \\
\hline Atomx / Teledyne Tekmar & $\begin{array}{l}\text { Autosampler, P\&T. } \\
\text { For analysis of volatile organic compounds in soils } \\
\text { and waters. }\end{array}$ & [112] \\
\hline $\begin{array}{l}\text { AQUATek } 100 \text { / Teledyne } \\
\text { Tekmar }\end{array}$ & $\begin{array}{l}\text { P\&T autosampler. Automates the sample } \\
\text { preparation steps for analysis of liquid samples } \\
\text { utilizing a fixed volume sample loop filled using a } \\
\text { pressurization gas. }\end{array}$ & [110] \\
\hline $\begin{array}{l}\text { Stratum PTC Purge and } \\
\text { Trap Concentrator / } \\
\text { Teledyne Tekmar }\end{array}$ & $\begin{array}{l}\text { P\&T for liquid samples analysis. Has a precise } \\
\text { mass flow controller and several sorbent traps. }\end{array}$ & {$[110]$} \\
\hline $\begin{array}{l}\text { Tekmar } 3100 \text { / Teledyne } \\
\text { Tekmar }\end{array}$ & P\&T for solid and liquid samples analysis. & $\begin{array}{c}{[61} \\
75-76]\end{array}$ \\
\hline $\begin{array}{l}\text { Enrichment and } \\
\text { Desorption Unit EDU3 / } \\
\text { Airsense Analytics GmbH }\end{array}$ & $\begin{array}{l}\text { Trap/Thermal Desorption. Allows extraction of } \\
\text { such components as water, methane, ethanol, etc. } \\
\text { from samples. Can operate automatically in the } \\
\text { multicycle mode. }\end{array}$ & $\begin{array}{l}{[111,} \\
112]\end{array}$ \\
\hline $\begin{array}{l}\text { MultiPurpose Sampler } \\
\text { MPS / Gerstel GmbH \& } \\
\text { Co. KG }\end{array}$ & $\begin{array}{l}\text { Autosampler and sample preparation robot (HS, } \\
\text { SPME). Functions: derivatization and standard } \\
\text { addition; dilution and extraction; cooled or heated } \\
\text { conditioning and mixing; solid phase extraction; } \\
\text { disposable pipette extraction; evaporation of } \\
\text { solvents; automated weighing, centrifugation, } \\
\text { agitation and sonication. }\end{array}$ & [113] \\
\hline $\begin{array}{l}\text { Gerstel-Twister / Gerstel } \\
G m b H \& \text { \& } . K G\end{array}$ & Stir Bar Sorptive Extraction system. & [113] \\
\hline $\begin{array}{l}\text { Thermal Desorption } \\
\text { System (TDS) and } \\
\text { Thermal Desorption Unit } \\
\text { (TDU) / Gerstel GmbH \& } \\
\text { Co. KG }\end{array}$ & $\begin{array}{l}\text { Extraction of bulk samples in the Thermal } \\
\text { Extractor; enrichment on adsorbent tubes and } \\
\text { subsequent thermal desorption using the TDS; } \\
\text { automated thermal desorption of standard adsorbent } \\
\text { tubes in the TDS; automated desorption of the } \\
\text { GERSTEL Twister; automated thermal extraction } \\
\text { of up to } 196 \text { samples in } \mu \text {-vials; automated injection } \\
\text { of viscous or matrix-containing liquid samples to } \mu \text { - } \\
\text { vials and subsequent thermal extraction in the TDU. }\end{array}$ & [113] \\
\hline
\end{tabular}


